DOE/METC--91/0274

DE91 002070

\title{
Tar Sand
}

\section{Technology Status Report}

\author{
T. R. McLendon \\ T. C. Bartke
}

\begin{abstract}
U.S. Department of Energy
Office of Fossil Energy

Morgantown Energy Technology Center

P.O. Box 880

Morgantown, West Virginia 26507-0880
\end{abstract}

January 1990 


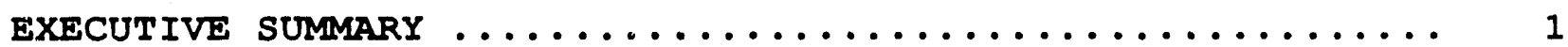

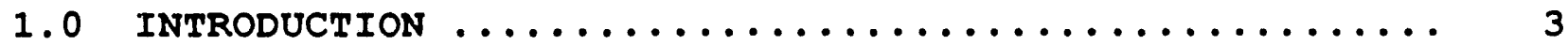

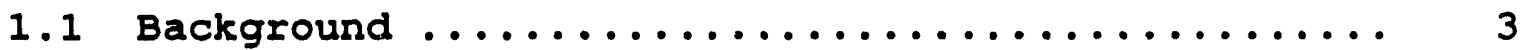

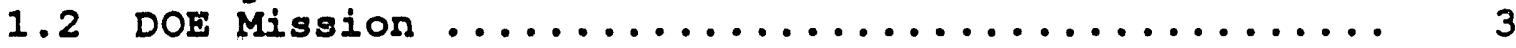

2.0 TECHNOLOGY DEVELOPMENT $\ldots \ldots \ldots \ldots \ldots \ldots \ldots \ldots \ldots \ldots \ldots$

2.1 Chemistry and Physics ................... 8

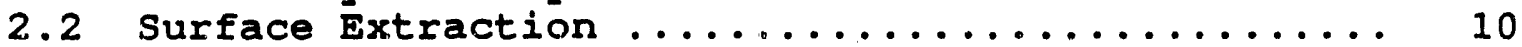

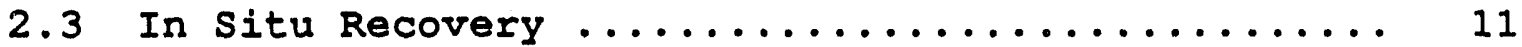

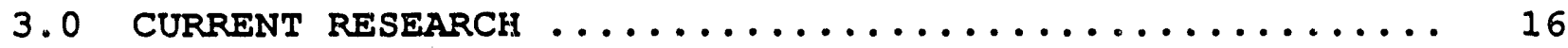

3.1 University of Utah .................... 16

3.1 .1 Fluidized Bed .................... 16

3.1.2 Fluidized-Bed Pyrolyzer/Heat-Pipe,

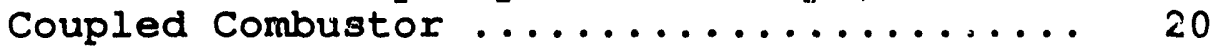

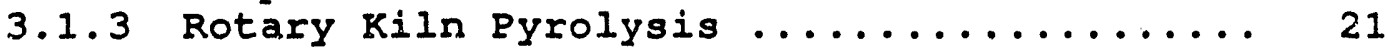

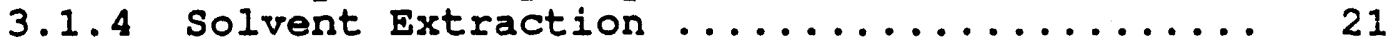

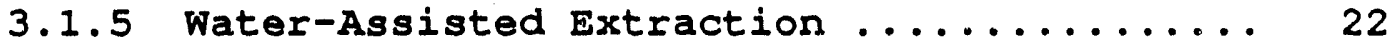

3.1.6 Upgrading and Product Utilization ....... 24

3.2 University of Arkans $1 s \ldots \ldots \ldots \ldots \ldots \ldots \ldots \ldots \ldots . \ldots \ldots$

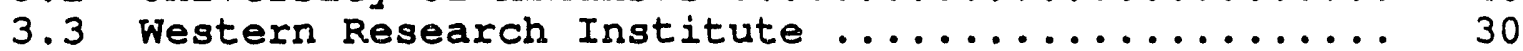

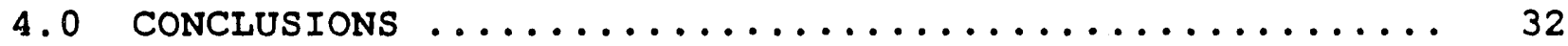

5.0 REFERENCES $\ldots \ldots \ldots \ldots \ldots \ldots \ldots \ldots \ldots \ldots \ldots \ldots \ldots \ldots \ldots \ldots \ldots \ldots$

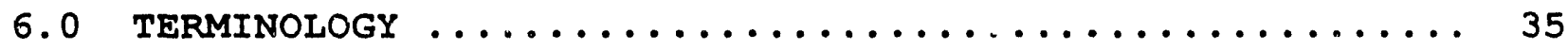


Definition of Tar Sand Compared to Heavy and

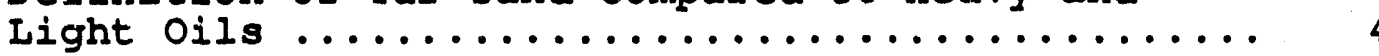

3 Distribution of U.S. Tar Sand Resources by State

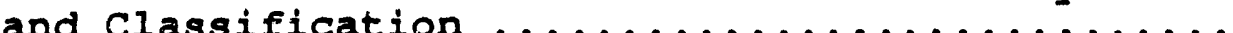

Comparison of Selected Estimates of Undiscovered Recoverable Conventional Oil. Resources for the

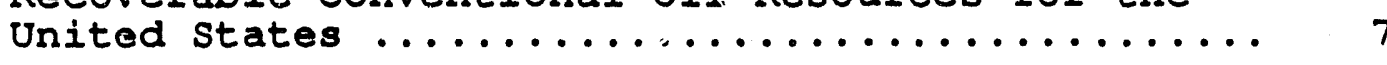

Comparison of U.S. to Cariadian Tar sand ........

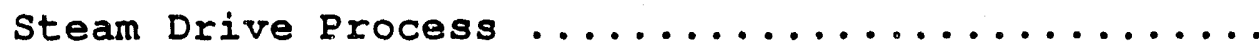

Forward and Reverse Combustion Processing Techniques

Schematic of University of Utah 4-inch, Fluidized-Bed Pyrolyzer

10 Iiquid, Coke, and Gas Partition for selected

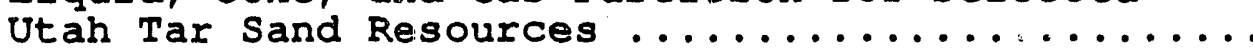

11 Effect of Reactor Residence Time on Iiquid

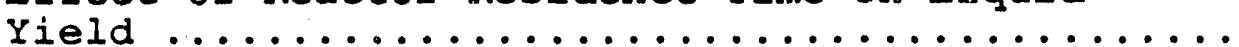

Effect of Reactor Temperature on Liquid Yield ...

13 Fluidized-Bed Pyrolyzer/Heat-Pipe, Coupled

Combustor

14 Simplified Schematic of Fluidized-Bed Pyrolyzer/

Heat-Pipe, Coupled, Coked, Sand Combustor in

Commercial Configuration

Rotary Kiln Pyrolysis Unit 


\section{EXECUTIVE SUMARRY}

The total, domestic tar sand resource is estimated to be about 60 billion barrels and is geographically scattered and geologically diverse. The domestic resource is consolidated and ojl wet, that is, the sand grains are cemented together and the oil sticks directly to the sand grains. Tar sand bitumen is solid at room temperature, with average molecular weights in excess of 500 and specific gravities of about 1.0. Typically, about 70 percent of the bitumen is soluble in a light, aliphatic solvent (e.g., hexane). This fraction is called maltenes. The remeining fraction is soluble in carbon disulfide and benzene and is called asphaltenes. Asphaltenes can lead to coke formation when heating bitumen to temperatures above $316{ }^{\circ} \mathrm{C}\left(600^{\circ} \mathrm{F}\right)$.

Extracting synfuels from tar sand resources offers a significant contribution to the nation's liquid fuels needs. Domestic liquid fuels production has declined at several hundred thousand barrels per day per year for the last several years. The U.S. liquid fuels supply is now at 52 percent imports. Since 1985, imports have increased by 3.4 milition barrels per day (MBbl/d) and domestic production has declined by $1.5 \mathrm{Mmbbl} / \mathrm{d}$. Proven crude oil reserves are down to 26.8 billion barrels. Undiscovered crude is an estimated 34.8 billion barrels. No mechanisms or activities are currently in place to reverse the trends of declining production and increasing imports.

Possible extraction methodologies include both in situ and surface extraction schemes. In situ recovery includes steam drive, steam cycling, and combustion. Less than 10 percent of the U.S. domestic resource is amenable to surface processing, which includes solvent-, thermal-, or water-assisted extraction schemes. If asphalt is a desired by-product, solvent-or waterassisted extraction is preferred since high recovery rates are needed for economics. Pyrolytic recovery upgrades the synfuel, which is good for refinery feedstock but not for asphalt production. Thermal extraction results in reduced average molecular weight, density, and viscosity by breaking down the larger molecules. Solvent recovery economics are sensitive to solvent losses in product or on tailings.

The research program supported by the U.S. Department of Energy (DOE) includes a variety of surface extraction schemes. The University of Utah has process development units (PDU) employing fluidized bed, hot, water-assisted, and fluidizedbed/heat-pipe, coupled combustor technology. Considerable process variable test data have been gathered on these systems: (1) a rotary kiln unit has been built recently; (2) solvent extraction processing is being examined; and (3) an advanced hydrogenation upgrading scheme (hydropyrolysis) has been developed.

The University of Arkansas, in collaboration with Diversified Petroleum, Inc., has been working on a fatty acid, solvent extraction process. Oleic acid is the solvent/surfactant. 
Solvent is recovered by adjusting processing fluid concentrations to separate without expensive operations.

Western Research Institute has a PDU-scale scheme called the Recycle Oil pyrolysis and Extraction (ROPE) process, which combines solvent (hot recycle bitumen) and pyrolytic extraction.

As this variety of research shows, liquid fuels recovery is sensitive to process/resource interactions. And, because the domestic resource is so varied, it is necessary to develop several approaches to tar sand recovery. 


\subsection{INTYRODUCTION}

\subsection{Background}

Tar Sand is defined as any consolidated or unconsolidated rock, exclusive of coal, gilsonite, or oil shale, that contains a hydrocarbonaceous material with a gas-free bitumen viscosity greater than 10,000 centipoise (CP) at reservoir temperatures. Figure 1 graphically relates tar sand to heavy and light oil (Kuuskraa 1985).

The tar sand resource base of the United States is composed of approximately 550 occurrences broadly distributed over 22 states, with the major deposits located in Utah, Alaska, Alabama, Texas, California, and Kentucky. Figure 2 (Marchant 1985) illustrates the geographic scatter and implies the geologic diversity of the deposits. In addition, hydrocarbon and mineralogical properties vary widely between deposits.

The total tar sand resource base was estimated by Lewin and Associates (Kuuskraa 1985) to include measured and speculative resources of 61.7 billion barrels of oil in place, and may approach 100 billion barrels with additional resource characterization. Figure 3 (Kuuskraa 1985) illustrates the distribution of tar sand resources by state; measured versus speculative resources are also shown. Since tar sand has had no significant commercial development in the U.S., little effort has been expended to discover and evaluate resources.

Tar sand bitumen is solid at room temperature. Most domestic tar sand is consolidated. In general, the mineral matrix is nearly all fine-grained quartz, or modified quartz, with $50 \%$ by weight being less than $0.3 \mathrm{~mm}(300 \mu \mathrm{m})$. Grains are normally cemented by a carbonate (e.g., calcite or dolomite). References to clays in tar sand literature may refer to fines, not to illite or kaolinite. Some tar deposits in California are in diatomaceous earth but these are exceptional cases.

\subsection{DOE Mission}

The Assistant Secretary for Fossil Energy (ASFE), U.S. DOE, has established a program consistent with the National Energy Policy Plan V (NEPP V) to "foster an adequate supply of energy at a reasonable cost." Tisis plan calls for a national energy policy, which "encourages research and development of new and alternative energy technologies that may help ensure adequate supplies long into the future."

As an alternative energy technology, the Tar sand Program is primarily concerned with liquid fuels production. In addition, 


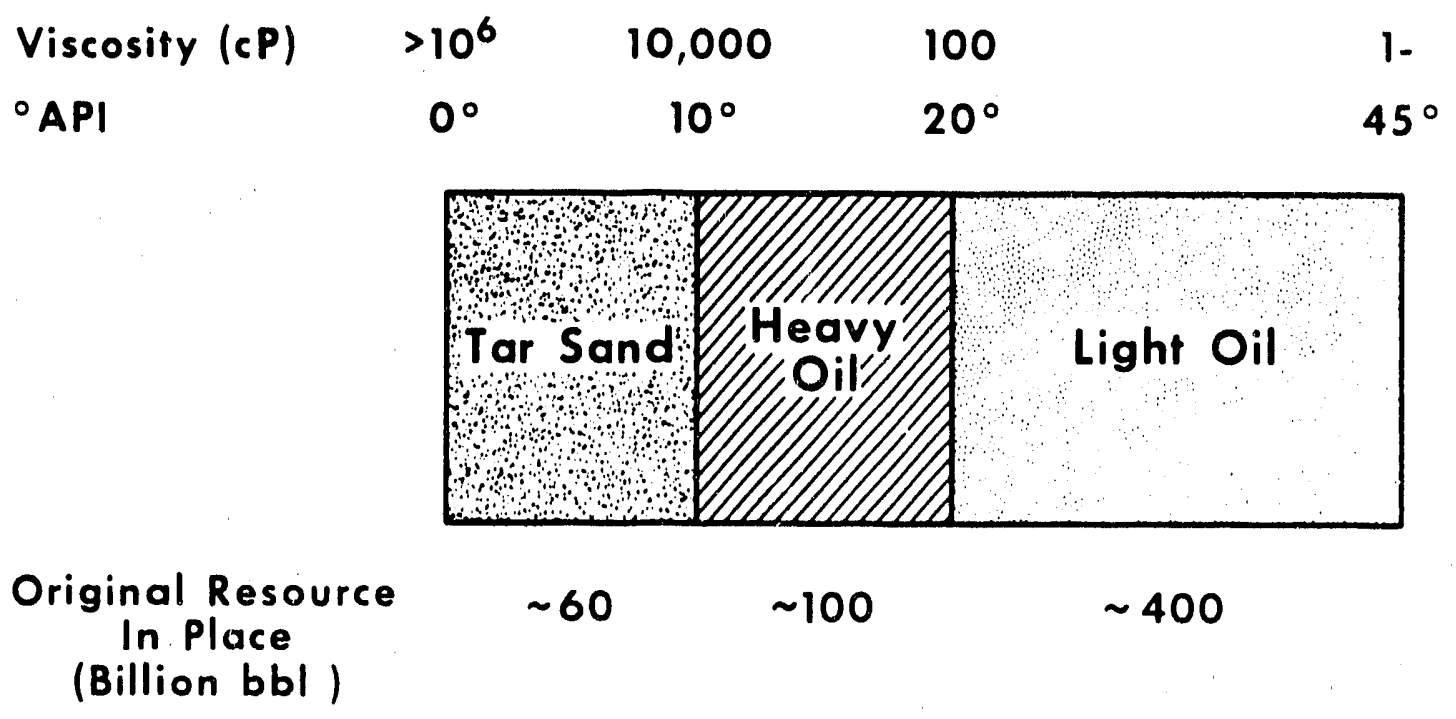

Eigure 1. Definition of Tar Sand Compared to Heavy and Iight Oils

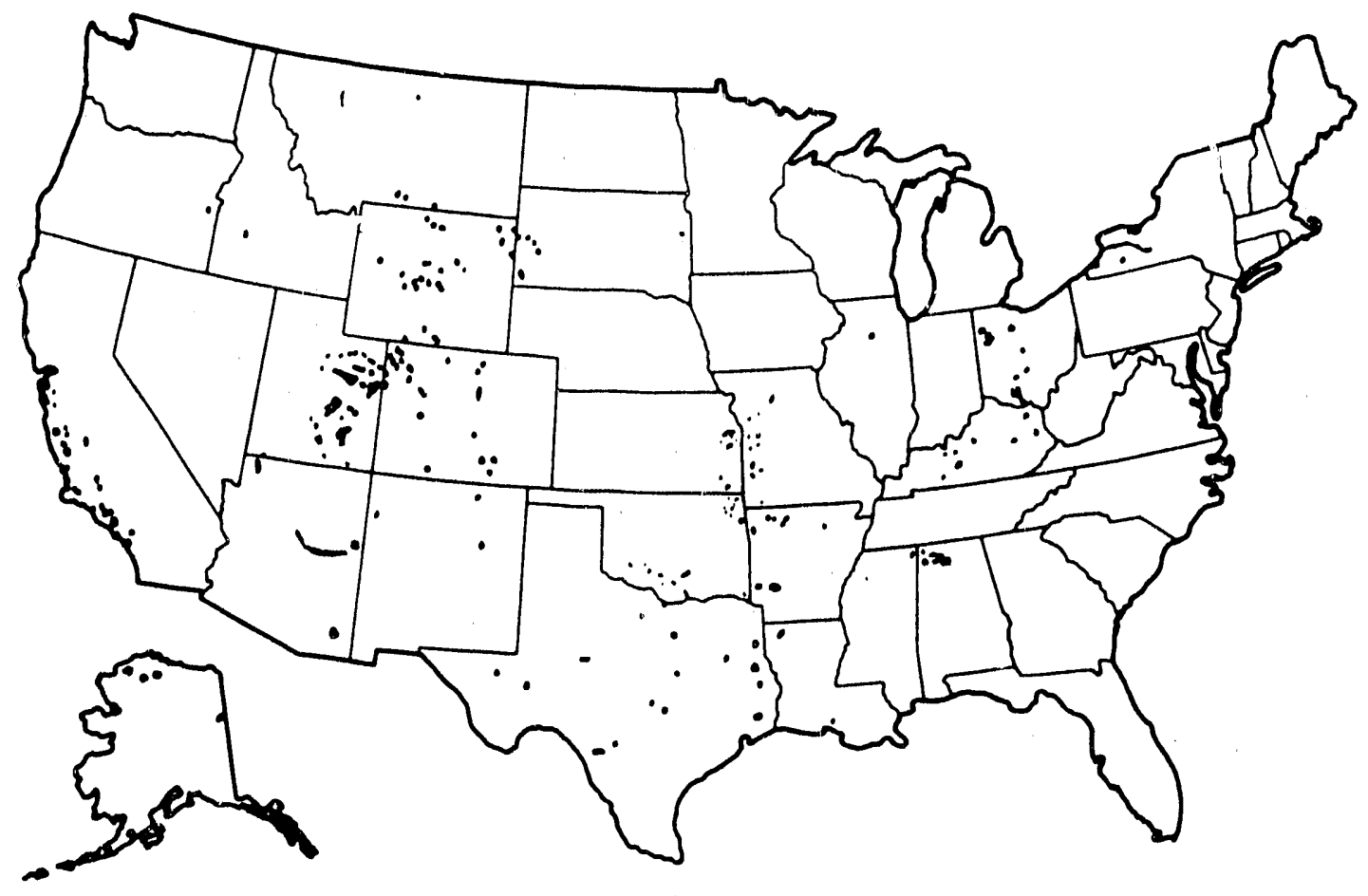

Figure 2. Tar Sand Occurrences in the U.S. 


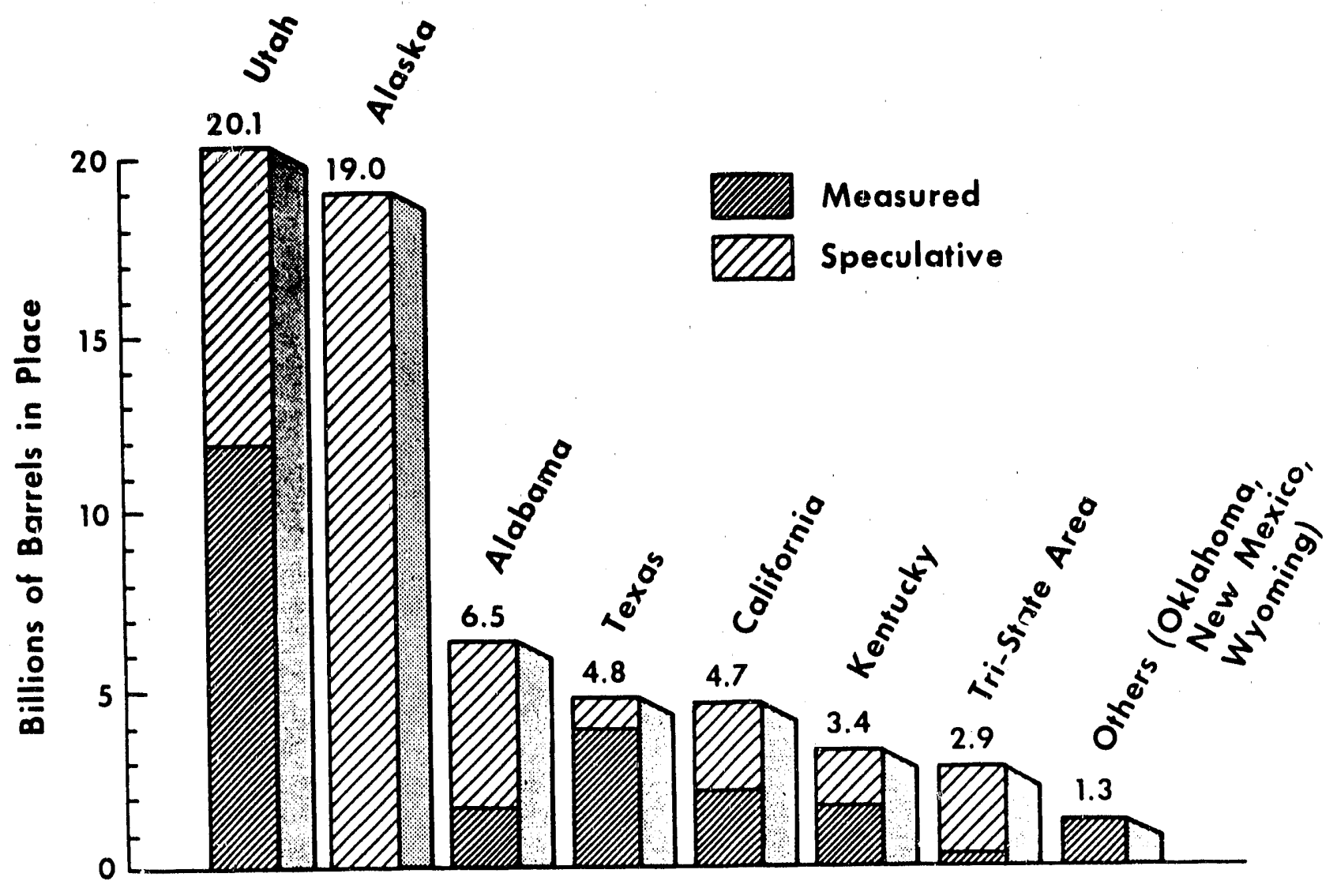

\section{Figure 3. Distribution of U.S. Tax Sand Resources by state and Classification}

DOE must ensure that its extraction technologies meet public health, safety, and environmental quality requirements.

Ample fossil energy supplies are present in the U.S. with the exception of conventional liquid fuels. The state of Wyoming alone has about 1 trillion tons of low sulfur coal (U.S. DOE 1978). At current use rates of less than 1 billion tons per year, this single deposit contains 1000 years of domestic supply. The Green River Formation of Colorado, Wyoming, and Utah has an estimated oil shale resource of 4 trillion barrels (Baughman 1978). At current use rates of petroleum (about $16 \mathrm{MMbbl} / \mathrm{d}$ ), that formation contains nearly 700 years of domestic supply. If only 10 percent of those resources are considered reserves, ample fossil energy is available to the nation for the next 70 years. only a limited geographical area can provide all the domestic coal and petroleum needs, provided the oil shale and coal can be economically converted to refinery feedstock. In addition, as of December 31, 1988, proved domestic gas reserves were about 168 trillion cubic feet and annual usage was less than 17 trillion cubic feet dry (U.S. DOE Energy Information Agency 1989 a [EIA]). The domestic unconventional gas resource has been estimated at 12.6 quadrillion cubic feet. If 10 percent of the 
unconventional gas resource is economically recoverable, a supply of 70 years is available.

The immediate problem with the U.S. domestic energy picture is the liquid fuels supply. Proved petroleum reserves as of December 31, 1988, were listed as 26.8 billion barrels (EIA 1989a). The EIf gives the daily consumption as more than $17 \mathrm{MMbl} / \mathrm{d}$ (EIA 1989b). What EIA presents as liquids is a misleading estimate. The domestic production of about $1.5 \mathrm{Mmbbl} / \mathrm{d}$ of natural gas liquids actually contains only about 300,000 barrels per day of pentanes, with the balance being ethane, propane, and butane. This reduces the 1989 average daily production of actual domestic crude oil to about $8 \mathrm{Mmbl} / \mathrm{d}$. The amount of imported crude oil and petroleum products were also nearly $8 \mathrm{Mmbl} / \mathrm{d}$ or about 50 percent imports (EIA 1989b). The problem is growing steadily. Since 1985, the amount of crude oil and product imports has risen by nearly $3.4 \mathrm{mmbl} / \mathrm{d}$. At the same time, domestic crude oil pxoduction has fallen by about $1.5 \mathrm{MLbl} / \mathrm{d}$. This is a natural result of the dramatic decline in exploration and depletion of existing fields.

The long term picture is discomforting. Figure 4 (U.S. Geological Survey [USGS] 1989) shows the estimated undiscovered oil reserves by year by the USGS and selected commercial interests. The lower, recent estimates resulted from the disappointingly low discover rates of the massive exploration efforts of the last 16 years. Vast reservoirs of oil are yet to be found in this country. Until liquid fuels uses change, this nation will have to produce liquid fuels from non-traditional sources or import-increasing quantities of liquid fuels. The U.S. DOE Tar Sand Program will develop tar sand extraction technology to assist in the inevitable, domestic liquid-fuels shortage.

Commercialization of domestic tar sand resources has faltered because of insufficient economic motivation. Bitumen from tar sand is currently projected to be more expensive than crude oil. Since no domestic industry exists, projected production costs must be estimated. However, operating and engineering data from the Canadian industry are available. The Alberta Oil Sand Technology and Research Authority funded a project by Partec Lavelin to evaluate the economics of two types of oil sand bitumen extraction processes, one of which was based on existing Canadian hot, water-extraction technology (Taciuk 1 li 5 ). The plant produced 106,418 barrels per day of upgraded $\left(37^{\circ}\right.$ API) synthetic crude by coking and hydrotreating hot, water-extracted bitumen. Plant siting was in Ft. McMurray, Alberta, Canada. Costs were originally in 1984 Canadian dollars. Converting to U.S. dollars and projecting to the present at a 5 percent per year inflation rate yields $\$ 11.58$ per barrel operating costs in 1990 U.S. dollars. Capital costs were converted to U.S. dollars and adjusted to 1990 U.S. dollars by the current plant cost index. Using a 25-year plant life, a 50/50 debt-equity ratio, 


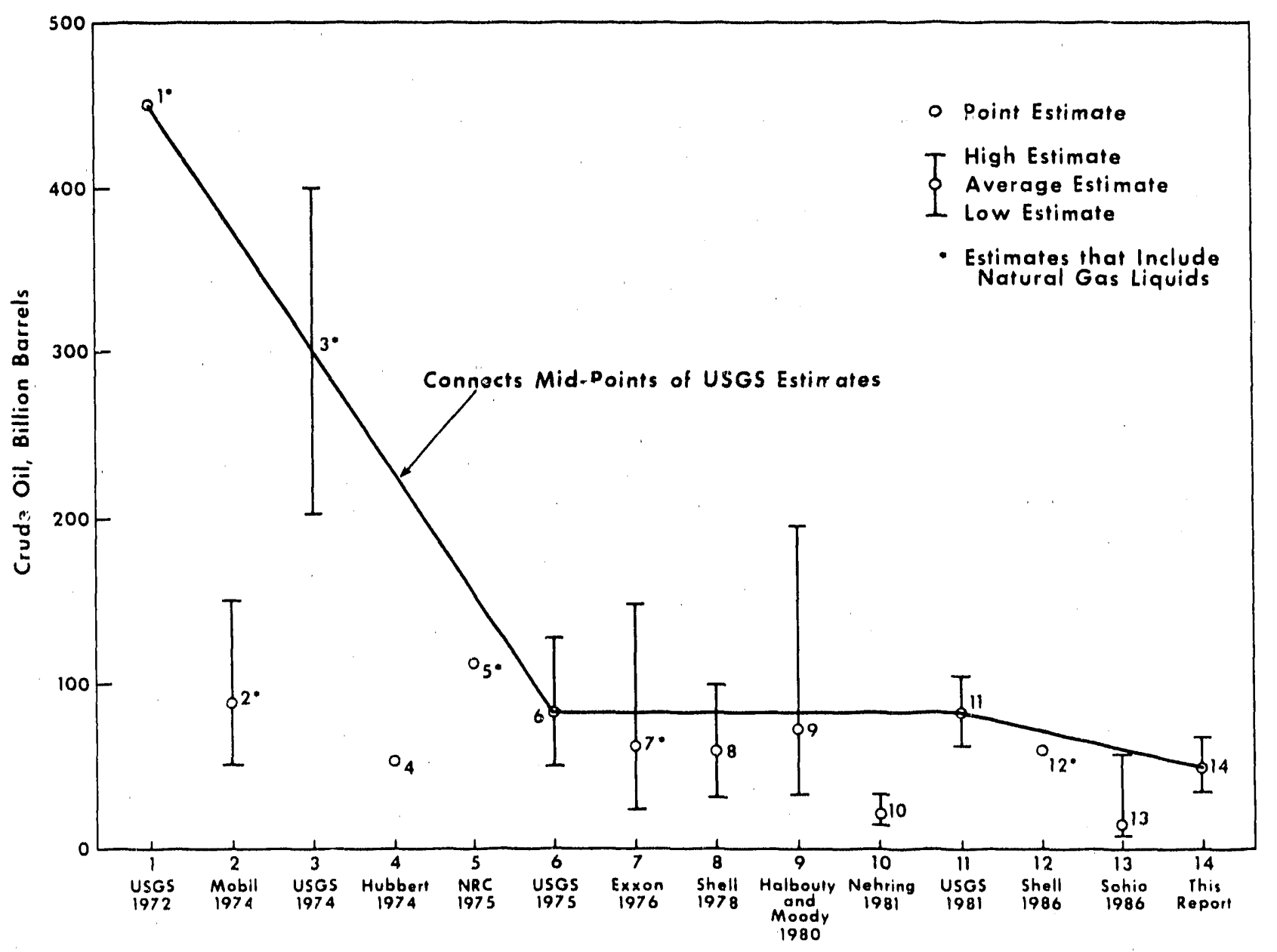

Higure 4. Comparison of Selected Instimates of Undiscovered Recoverable Conventional Oil Resources for the United states

10 percent interest on debt, and 20 percent return on investment before taxes yields a capitalization cost of $\$ 13.18$ per barrel and a required selling price of $\$ 24.76$ per barrel. A $75 / 25$ debtequity ratio under the same conditions gives a required selling price of $\$ 22.82$ per barrel.

The most recent economic assessment of domestic tar sand production comes from J.W. Bunger and Associates of Salt Lake City, Utah, using the latest modified water-assisted extraction technology for a site lowated in Utah (Bunger 1990). The plant size is 30,000 barrels per stream day with an overall plant service factor of 0.9. Product is an upgraded (hydrocracking and cokingl synfuel for refinery feedstock. Operating costs are $\$ 16.1$ per barrel with no royalty costs included. Capital costs are $\$ 630$ million. A debt-equity ratio of $75 / 25$, an interest rate of 10 percent, and a before-tax return on investment of 20 percent yields a capitalization cost of $\$ 8.5$ per barrel. Selling price would be $\$ 24.6$ per barrel under these conditions. Considerable economies of scale are possible by increasing the rate to 50,000 barrels per day, which would significantly lower cost. 


\subsection{THECHOLOGY DEVELOPMENT}

\subsection{Chemiatry and Physics}

Tar sand bitumen is a dense hydrocarbon that is so viscous at room temperature that it is solid. It has significant amounts of compounds insoluble in alkane solvents (e.g., hexane) and has average molecular weights in excess of 500. Maltenes are the materials in the fraction of bitumen soluble in alkane solvents. The fraction of bitumen soluble in carbon disulfide and benzene, but not in light paraffin, is called asphaltene. Asphaltenes (1) have molecular weights of 2000 or more and densities as high as $1.22 \mathrm{~g} / \mathrm{cm}^{3}$; (2) are polycyclic, condensed, aromatic compounds that are normally polar; (3) contain oxygen, nitrogen, sulfur, and sometimes metals; and (4) are polynuclear aromatic structures with long, alkyl side chains linked together with methylene or etheric linkages. The heavy asphaltenes have high boiling temperatures compared to the maltenes and have a tendency to thermally degrade to coke and vapors at temperatures lower than their boiling points.

Asphaltenes present in domestic tar sand benefit tar sand bitumen as an asphalt source. Some resources contain nearly 50 percent asphaltenes. Deposits have been mined, mixed with aggregate, and spread directly on roads. However, large amounts of asphaltenes present problems as potential refinery feedstock because of increased coking tendencies, large molecular size, and the presence of oxygen, nitrogen, and sulfur.

Canada supports vast tar sand/heavy oil deposits and a thriving extraction (at least 10 times the domestic resource and several hundred thousand barrels per day production). The U.S. and Canadian resources are fundamentally different. The Canadian resource is water wet. That is, the ample water present has a stronger affinity for the sand particles than does the bitumen. The domestic resource is essentially oil wet. Figure 5 illustrates the difference. This characteristic of U.S. tar sand having no water film between the bitumen and sand precludes direct use of the simple, Canadian, water-assisted extraction technology. This process mixes oil sand and water with considerable agitation, and the sand and bitumen separate. The domestic resource is not so easily extracted in a water slurry because the oil does not readily detach from the sand.

Regardless of how the bitumen is removed, the product is viscous and contains significant percentages of oxygen, nitrogen, and sulfur. The bitumen nitrogen content is in the range of .5 to 1.5 percent, and sulfur is usually less than 1 percent but can be up to 4 or 5 percent in some deposits. Oxygen is more variable and can range from 1 to 7 percent. Oxygenates can cause polymerization at elevated temperatures, which increases plugging problems when in situ retorting is attempted. 


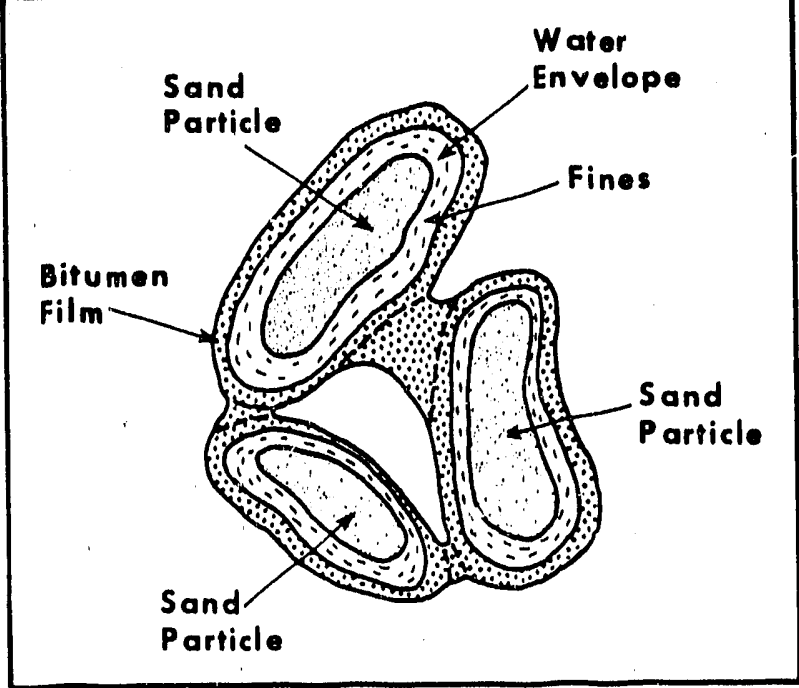

CANADIAN

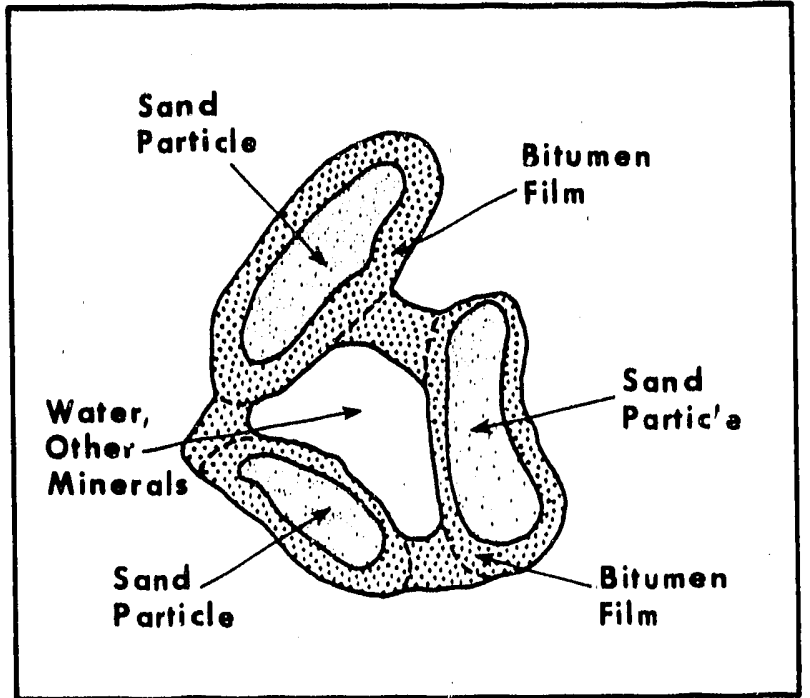

U.S. DOMESTIC

Eigure 5. Comparison of U.S. to Canadian Tar Sand.

Two broad categories of extraction processes include the majority of bitumen recovery variations: (1) in situ extraction through well bores; (2) mining with surface plant extraction. The in situ extraction category includes

- Steam drive processes.

- Combustion processes.

- Solvent injection processes.

The surface extraction processes include

- Thermal (pyrolysis).

- Solvent.

- Water assisted.

Each of the in situ extraction processes introduces into injection wells a viscosity-reducing medium, which either heats up or otherwise loosens bitumen in the formation sufficient to generate hydrocarbon flow to production wells. Surface extraction processes all require some form of mining the tar sand and transportation to an extraction plant. The properties of both the mineral and organic components of each individual resource 
vary considerably. In addition, each type of extraction process yields a slightly varied bitumen product. Thus, for each reservoir an extraction procoss must be carefully chosen to obtain the desired product characteristics.

\subsection{Surface Extractiun}

All surface processes require mining of the tar sand, grinding or crushing to appropriate feed sizes, and processing a.nd cisposing of the processed sand. Therefore, surface extraltion generally disrupts the environment more than in situ prucessing. However, surface extraction is a more efficient utilization of the resource. Additionally, numerous deposits are so near the surface that in situ recovery is not possible or zecessary. The amount of overburden is the economic constraint on strip mining.

Thermal processing involves heating the tar sand to vaporize the volatile compounds and pyrolytically decomposing the larger, non-volatile molecules into more volatile, smaller ones and residual carbon (char or coke). This "upgrading" reduces the viscosity, pour point, and average molecular weight. The loss of bitumen to coke in the pyrolysis process is in the range of 10 to 30 percent by weight depending on conditions. Gas yields are more variable and are typicaliy in the range of 10 to 30 percent by weight. Thus, thermal processing can have significant liquid product losses compared to the original bitumen. This may be desirable if the intent is to produce an upgraded refinery feedstock. If the market product is paving asphalts or some specialty chemicals, thermal extraction may result in too much product loss. Hovever, the coke and gas by-products may be utilized as fuels to drive the pyrolysis process.

The water-assisted process depends upon intense mechanical shear forces to dissociate the bitumen from the sand particles. Severe mixing and agitation is done by turbines or paddles. Bitumen viscosity and bitumen-mineral interfacial interactions are the most significant controlling parameters. In practice, raising water temperature and adding viscosity-reducing agents aid in bitumen extraction. Also, adding wetting agents, pH adjustments, and air frothing increase separation efficiency.

Water-assisted processing is commercially practiced in the Canadian tar sand industry. However, the Canadian resource is water wet. The domestic tar sand resource is typically oil wet; hence the Canadian technology is not directly applicable. More stringent U.S. environmental regulations present problems not present in Canada. Because all the bitumen is not romoved from the sand, tailings disposal can be an environmental problem, particularly if diluents are added to the raw tar sand to reduce bitumen viscosity. Bitumen retention is a function of total surface area, and the smaller the particle the larger the surface-volume ratio. Therefore, copious fines can help cause 
excessive bitunen retention. In arid regions, water-assisted extraction may be restricted due to process water costs; therefore, maximum utilization of recycle water is necessary.

Solvent extraction is similar to the water-assisted scheme except that chemical rather than mechanical forces are the primary separation mechanisin. Numerous solvents and combinations of solvents have been proposed. Factors controlling process efficiency are bitumen and solvent retention on the sand and ease of bitumen-solvent separation after extraction. Since the solvent is usually much more expensive than the bitumen, solvent losses govern the economics. It is not practical to lose expensive solvent to recover cheap bitumen. Also, tailings disposal can be an environmental concern. As with the water-assisted process, copious fines cause excess solvent and bitumen retention on the sand.

\subsection{In Situ Recovery}

Current economic conditions and technology development favor surface extraction methods. However, because of mining constraints, the bulk of the domestic tar sand resource is not amenable to surface processing. Therefore, in situ extraction techniques must be developed to enable exploitation of a laige percentage of the resource.

In situ extraction includes thermal (combustion or the injection of steam, hot water, or other heat source inputs) and solvent processes. Both of these processes introduce a fluid medium into the tar sand reservoir through wellbores to reduce the viscosity and to mobilize the bitumen to a production well. This viscosity reduction may result from (1) mixing with a solvent, (2) increased reservoir temperature, or (3) a combination of both, such as injection of $\mathrm{CO}_{2}$ with steam. Increased reservoir temperatures may be accomplished by steam injection and subsequent in situ combustion, or by other innovative heating processes such as radio frequency radiation.

of the thermal processes, two basic methods use steam (cyclic steam stimulation and steam drive) and two techniques use fire (forward combustion and reverse combustion). Cyclic steam stimulation, commonly known as "huff-and-puff," is the simplest and most direct of the in situ methods. This method consists of pumping high-pressure steam down a well for a period of time, then shutting in the well to allow heat soaking of the reservoir. The heat from the steam reduces the viscosity of the bitumen, mobilizing the oil to the wellbore. After the steam is shut off, the same well is used to pump out the mixture of steam, water, and bitumen. When the percentage of bitumen in the mixture is reduced to a predetermined level, production stops and steam is again forced into the deposit. This process is shown in Figure 6. The cycle is repeated until the operation is no longer 


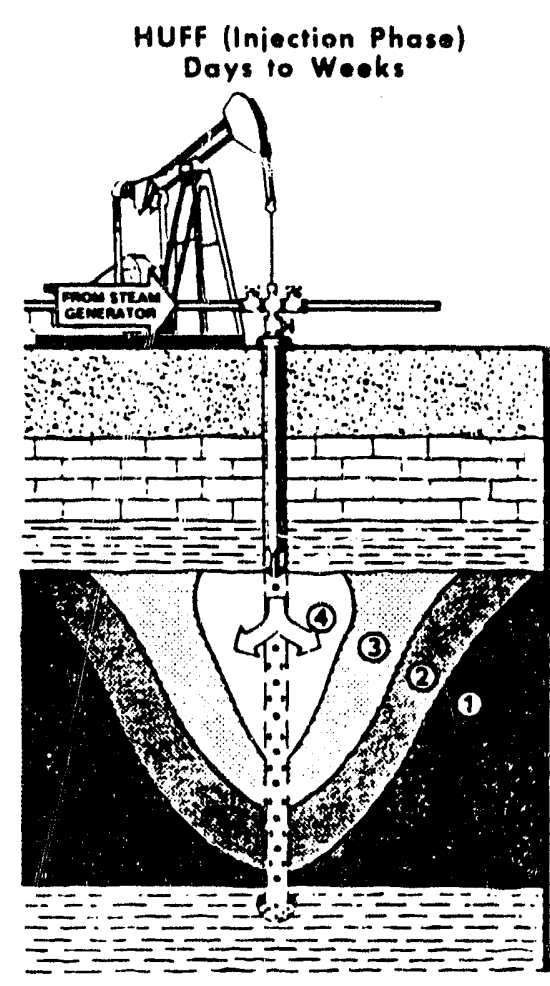

(1) Viscous Oil

(2) Heated Zone

(3) Condensed Steam Zone
SOAK (Shut-in Phase) Daye

(Dissipating Heat ihins Oil)
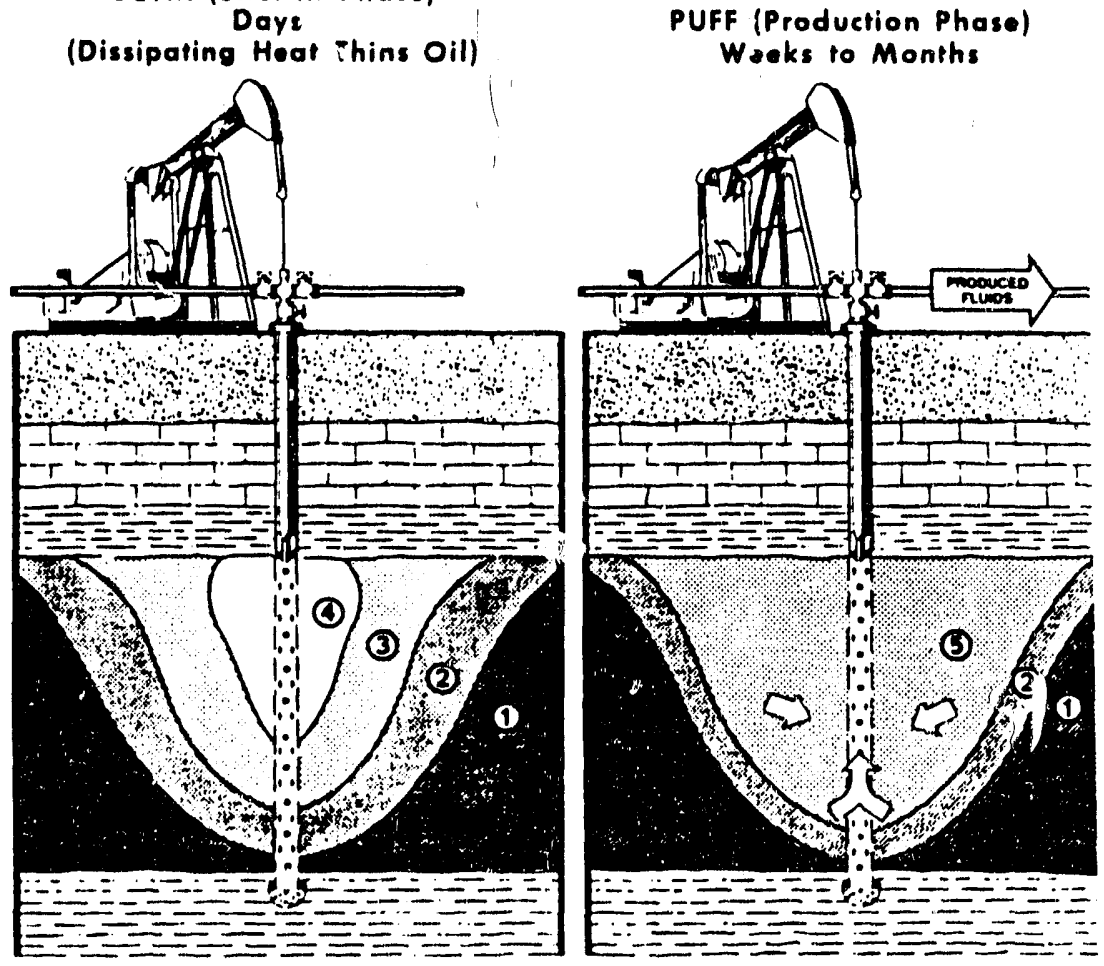

(4) Steam Zone

(5) Flowing Oil and Condensed Steam

Eigure 6. Cyclic steam stimulation

producing enough oil to be profitable, typically 20 to 30 percent of the oil in place.

Steam drive requires two types of wells, one to inject the steam into the deposit and the other to produce the oil. The steam front moves from the injection well toward the surrounding production wells, driving the heated bitumen ahead of it through the sand. The oil is pumped to the surface at the production wells. Figure 7 illustrates this scheme. The initiation of steam drive requires fluid flow communication between injection and production wells. This is often a major, and sometimes extraordinary, task in consolidated tar sand, requiring much cyclic steaming, directional drilling, fracturing, or other operational techniques.

In situ combustion methods use a fire drive instead of, or in combination with, a steam drive. With forward combustion, aix is injected through a well into the tar sand deposit, and the bitumen fuel is ignited. The fire acts on the bitumen much like a coking process, cracking some of the bitumen to produce coke, which fuels the fire, and heating the remainder to a vaporized or liquefied state. The combustion zone moves from the injection 


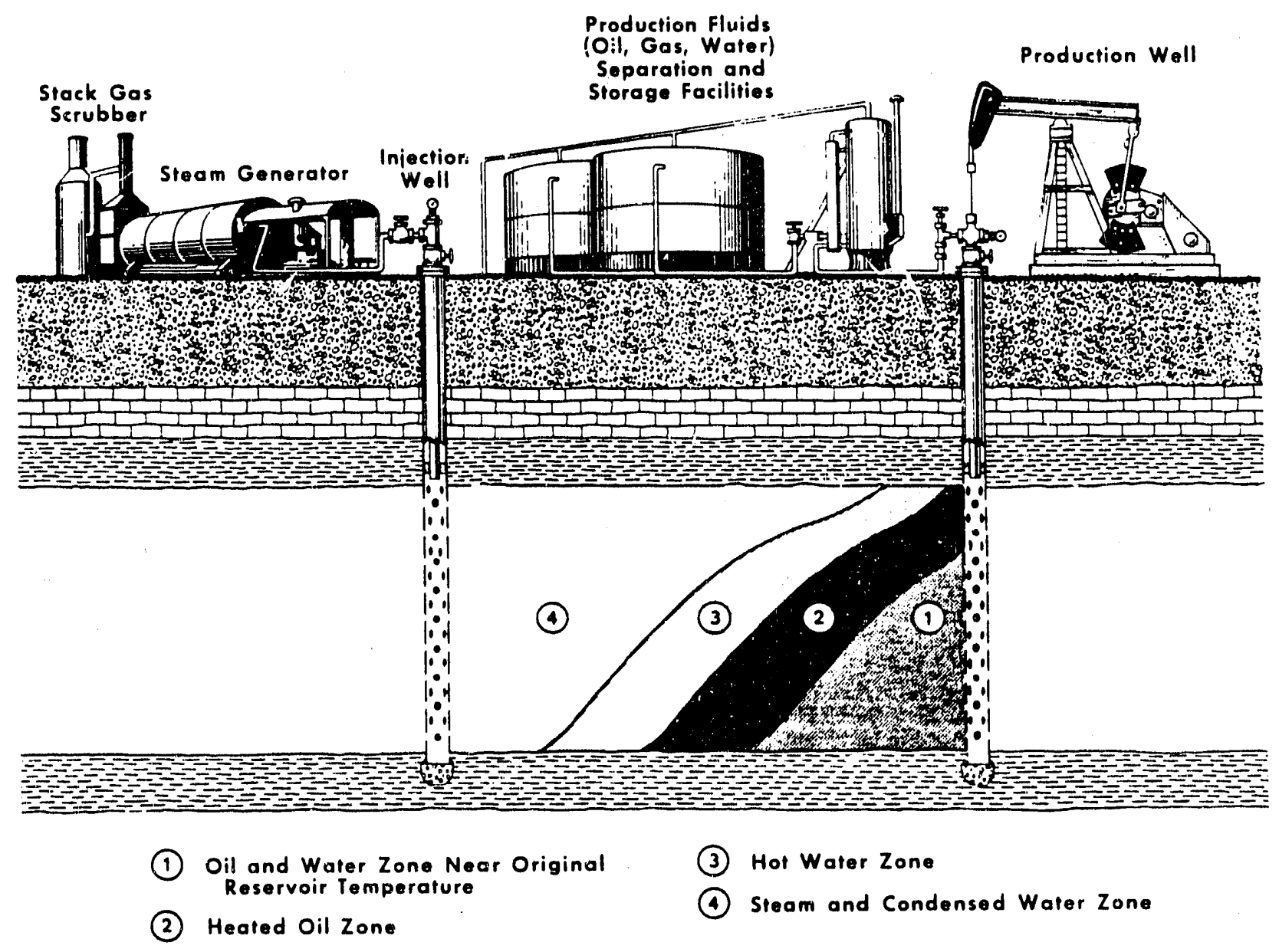

Figure 7. Steam Drive Process

well toward the production well, driving the mobile oil ahead of it. The oil is pumped to the surface at the recovery well. This technique is shown in Figure 8 . Steam is sometimes injected with the air or oxygen, which results in wet combustion.

As with forward combustion, two or more wells are required for reverse combustion. The difference is that the fire is ignited in the recovery well while air continues to be provided through the injection well. The fire moves toward the source of oxygen, from the recovery to the injection well, while the oil flows counter-currently under the pressure of the hot gases. This concept is illustrated in Figure 8 . Because the bitumen has been burned off behind the fire, the clean sand permits the hot oil to pass to the recovery well Reverse combustion is more commonly employed to establish well-to-well linkage and then is followed by a forward combustion or drive process to effect better oil-bitumen recovery.

In situ tar sand extraction has all the inherent problems of traditional petroleum production plus the added problem of high 

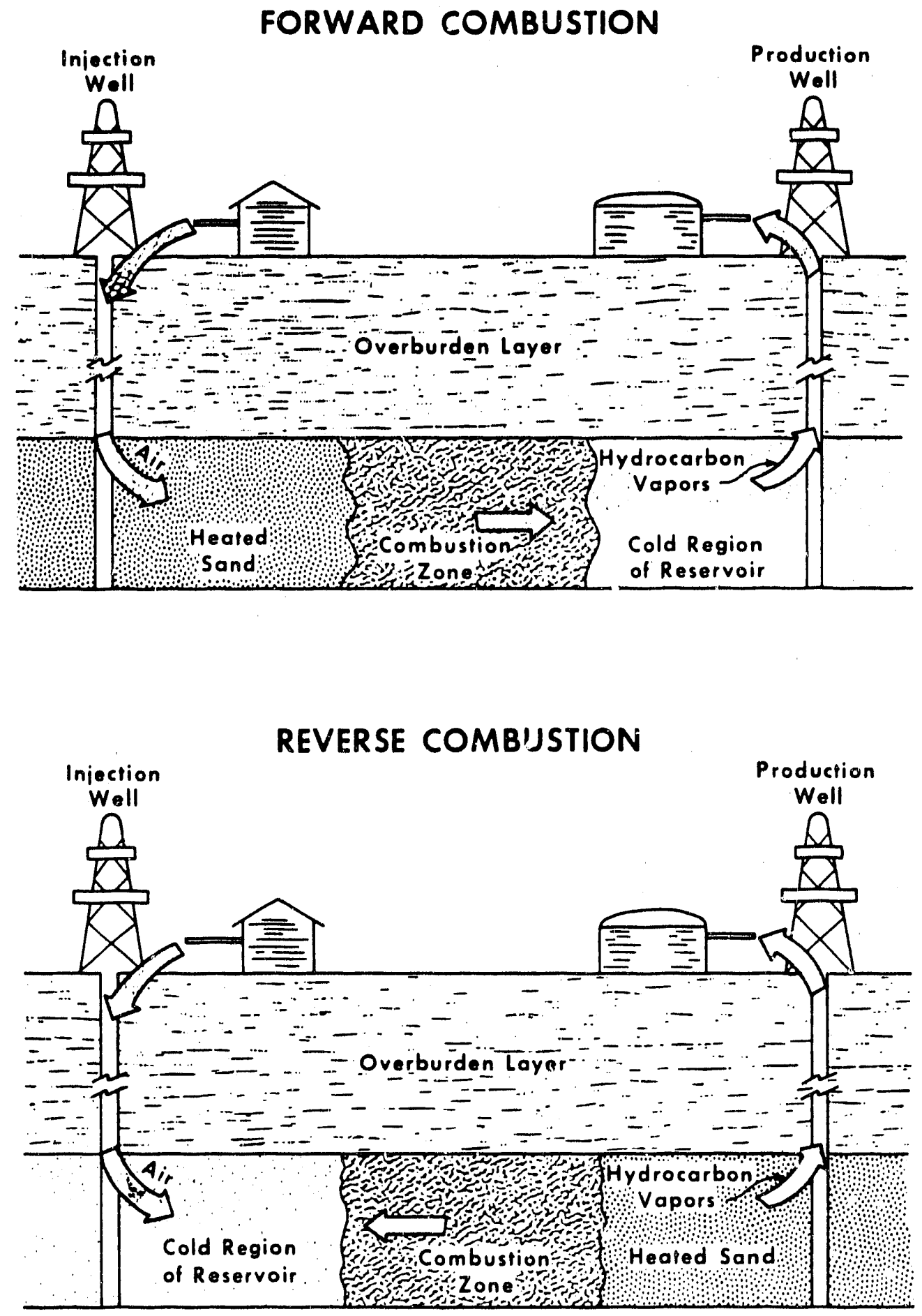

Figure 8. Forward and Reverse Combustion Processing Techniques 
viscosity. It is not simply a matter of heating the reservoir to mobilize the bitumen. If the bitumen cools down as it moves away from the source of heat, the reservoir can be plugged un by the heavy, viscous bitumen, and essentially all reservoir permeability can be lost. 


\subsection{CURREATT RESERRCH}

\subsection{Univeraity of Utah}

The Universicy of Utah has had a comprehensive program of tar sand extraction research since 1974. The work has concentrated on surface extraction schemes and fundamental product upgrading research. The University of Utah team has made considerabie technological advancement, and some of the extraction schemes could logically advance to the pilot-plant scale. A proposal for cost-shared, pilot-plant studies of a modified, hotwater, extraction process was prepared in 1990.

The extraction of bitumen from tar sand is relatively easily done; the constraint. is in the economics. DOE-supported research focuses on refining the technology to levels where extraction processes can compete with more traditional sources of refinery feedstock. Concomitant with devaloping technology is the constraint of environmental acceptability. Producing valuable byproducts, such as asphalt, may te the initial impetus to commercialization.

\section{1.: Fluidized Bed}

Fluidized-bed processing involves crushing tar sand into small particles $(0.6 \mathrm{~mm}$ and smaller). The tar sand is fed to a hot reactor where a fluidizing gas is injected into the bottom of the vessel. A range of gas velocities (depending on particle size, density and shape, and gas viscosity and density) lift the particles and suspend them in a fluid-like state. If the gas velocity is too high, the particles are swept out the top of the vessel.

In the range of fluidization velocities, the individual particles move more or less freely, contacting other particles and containing vessel surfaces. The net effect of the random particle motion (solid-to-solid contact) and the high gas velocity is to greatly increase heat transfer rates in fluid beds. Thus, fluidized beds are a thermally efficient pyrolysis process. The economics of material handling (e.g., size reduction and fines handling) need improvement to make fluidized-bed processing attractive.

The fluidized-bed research at the University of Utah started in the early $1970 \mathrm{~s}$ with a nominal 1.25 -inch diameter reactor and a maximum feed rate of 5 pounds per hour. The effort has now advanced to a 4-inch diameter unit that has continuously operated at a throughput of 41.4 pounds per hour. A schematic of the 4-inch unit is shown in Figure 9 (Oblad and Hanson ...988). 


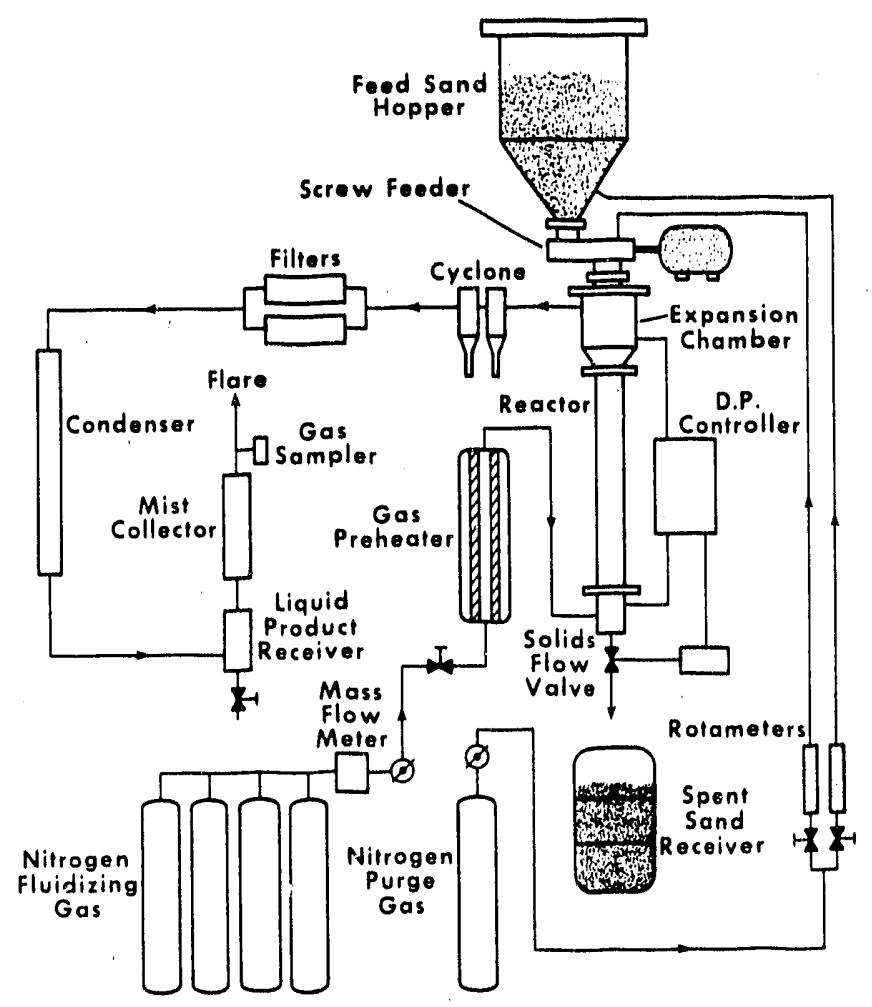

Figure 9. Schematic of University of Utah 4-Inch,

Nearly every Utah resource has been evaluated for processability by fluidized beds. Process variable studies have shown the more important parameters to be residence time and temperature in the pyrolyzer, and Conradson carbon residue values of the feedstock. Conradson carbon is determined by a destructive distillation laboratory test that indicates the native bitumen's coking tendency. Larger, complex, cyclic compounds tend to yield considerable amounts of coke residue when heated to pyrolysis temperatures. Figure 10 (Oblad et al. 1988) clearly shows that. bitumens with high, carbon residue values have higher coke and gas losses in fluidized-bed retorting. For example, the Whiterocks resource gets about 20 percent more liquid yield than the PR Spring South resource under identical operating conditions. The University of Utah research has shown the need to match processes to resources. Other thermal extraction methods have been shown to give different relative liquid yields for the different resources.

Fluidized-bed reactor residence time significantly affected oil yield. Figure 11 (Oblad and Hanson 1988) shows that as residence time increases, oil yields decrease. At zero residence 


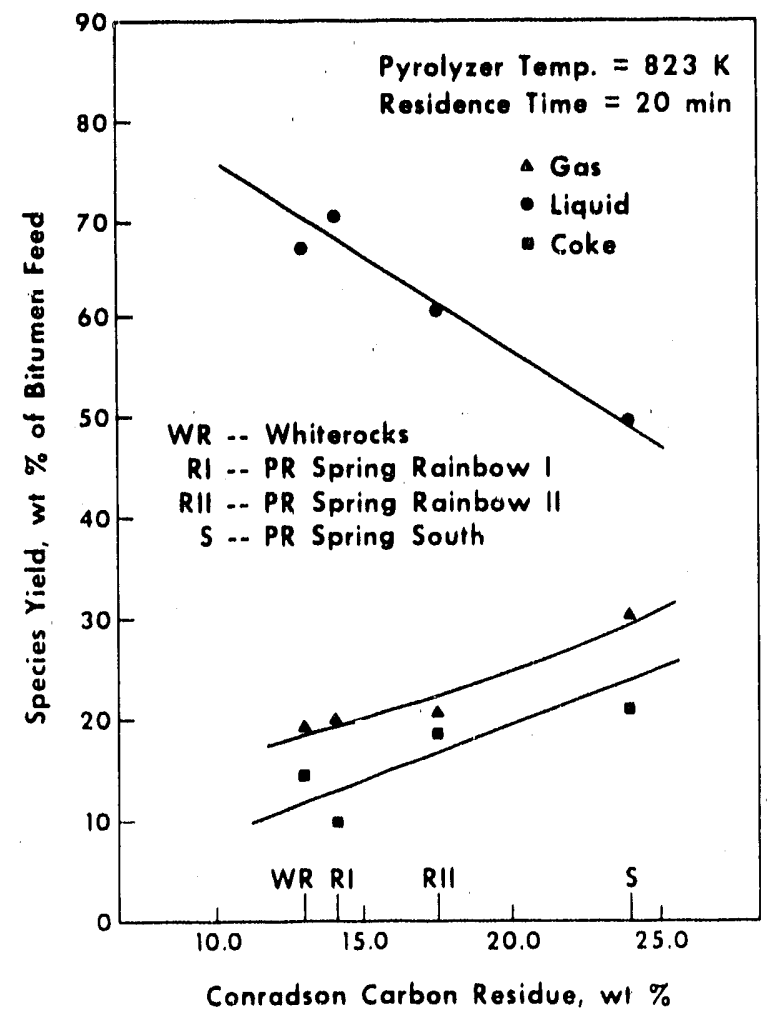
Figure 10. Iiquid, Coke, and Gas Partition for
Selected Utah Tar Sand Resources

time, there would be no conversion, so there is obviously an optimum residence time for the fluidized-bed system. For the experiments reported in Figure 11, residence times were varied by altering the flow rate. That is, reactor volume (hence mass) was held constant while flow rate was changed. Residence time is calculated from reactor mass divided by mass flow rate. Another way to alter residence time is to keep the flow rate constant and vary mass in the reactor. Either method introduces an additional factor to consider: the change of the ratio of fresh tar sand feed to hot spent sand in the reactor. The greater the residence time the greater the amount of hot spent sand to fresh feed. Any effect of total surface area of hot, coked, spent sand being exposed to bitumen (e.g., catalytic degradation or cracking) will, therefore, be determined by the above methods for changing residence time.

Reactor temperature (the temperature read by a thermocouple inside the reactor) also affects oil yield. This effect is shown in Figure 12 (Oblad and Hanson 1988). For all resources and residence times, reducing temperature to below $800 \mathrm{~K}$ increases liquid yield. Further reduction in temperature for five of the 


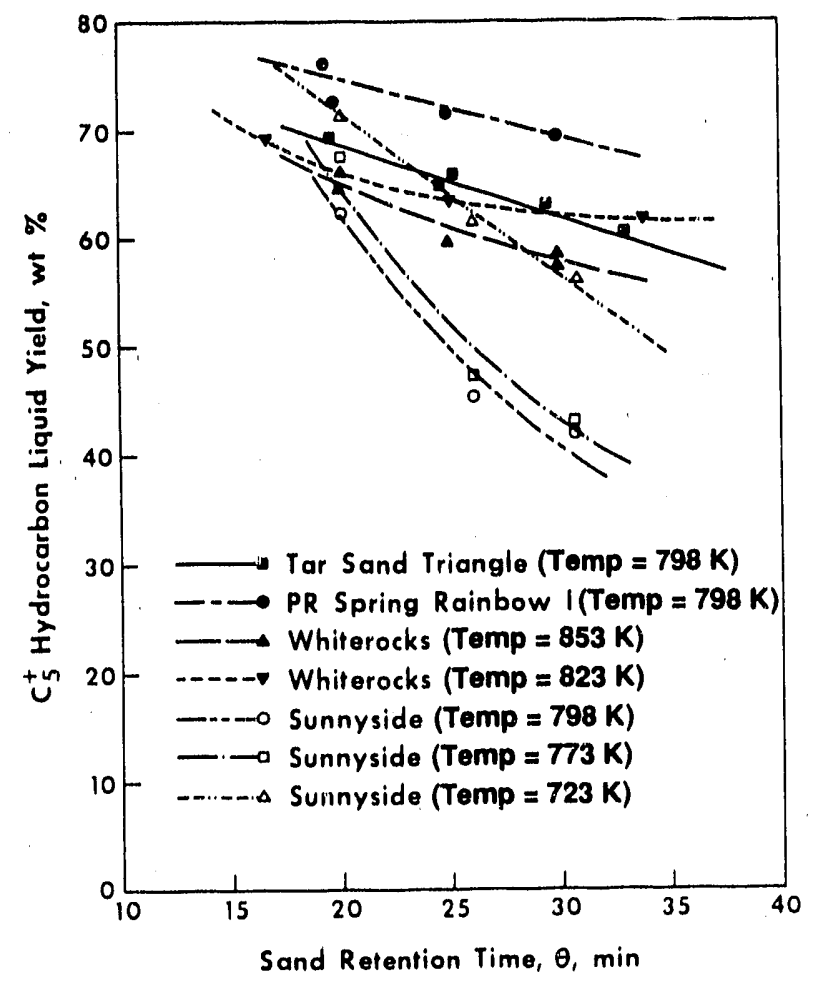

Higure 11. Effect of Reactor Residence Time on Liquid Yield

resource/time conditions shows an eventual decrease in liquid yield (concave downward curves). Therefore, for these five curved lines, there is an optimum reactor temperature. At reactor temperatures less than $400 \mathrm{~K}$, there will be no liquid production, since that temperature is too low to pyrolyze the bitumen. Therefore, even the straight lines on Figure 12 will eventually have an optimum as temperature is decreased.

Another feature shown in Figures 11 and 12 is that some resources are better than others for this extraction technology at all conditions. For example, Figure 12 shows that the PR Spring I resource gives more liquid yield at all temperatures than the PR Spring II resource.

The previous discussion shows how complicated testing process variables can be. Each resource is unique and there are many process/resource interactions to consider. Therefore, a program of developing several different extraction schemes is necessary, if more than a few of the tar sand deposits are to be exploited.

Future work in the fluidized-bed program at the University of Utah will focus on providing information for scale-up to 


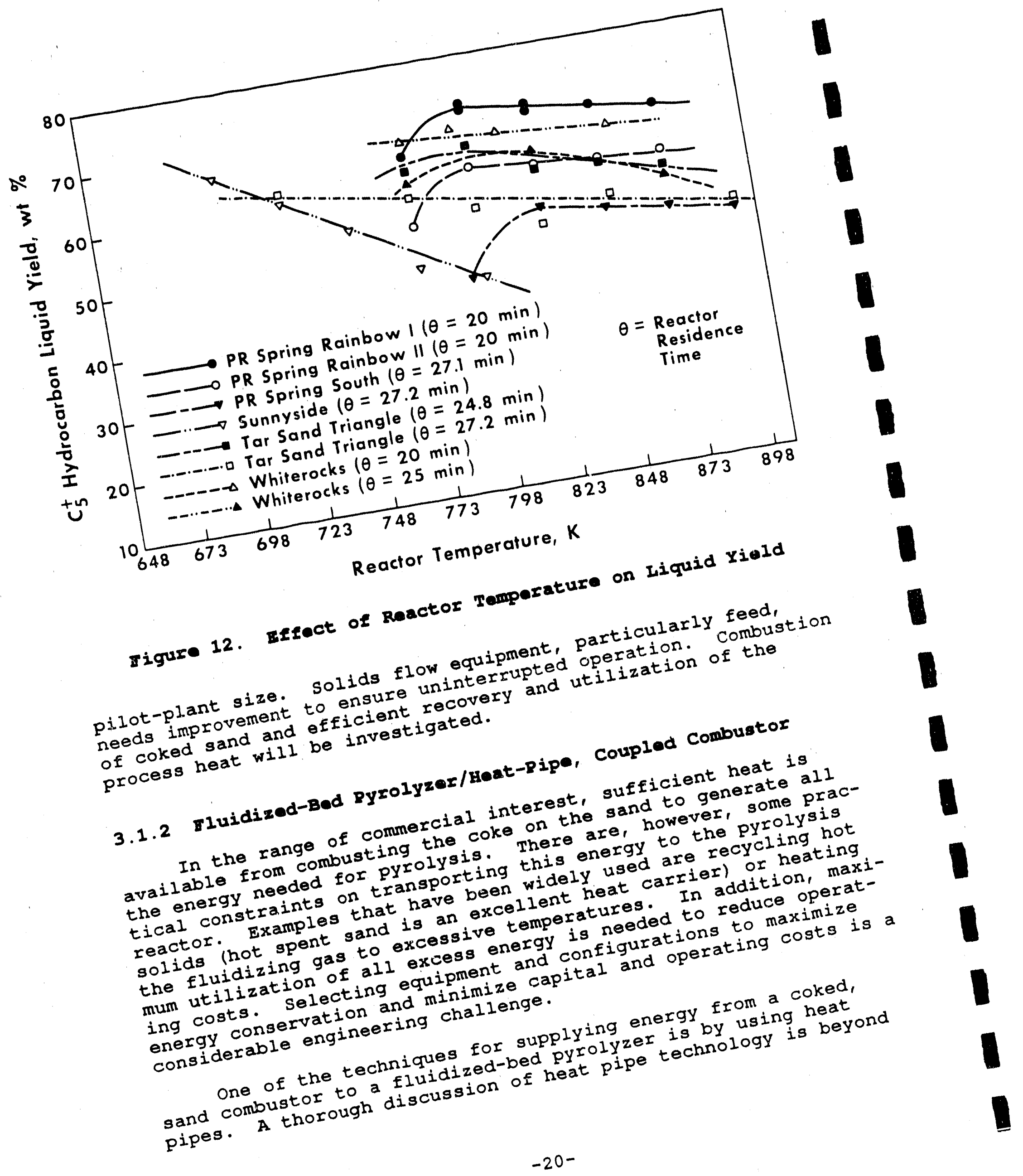


the scope of this paper, but a brief explanation is warranted. Heat pipes are an efficient method of transmitting large amounts of thermal energy from one process unit to another. One end of the closed, hollow pips is put in the heat source and the other is in the heat sink. The heat carrier vaporizes, expands in volume, and moves through the hollow tube to the cold end where the fluid condenses, liberating much thermal energy. The liquid is returned to the hot end by a wick material that lines the inside tube wall.

In tar sand pyrolysis application, the hot end is placed in the coked, sand combustor and the cold end in the pyrolyzer. There have seen several iterations of a fluidized-bed/heat pipe, coupled, coked sand combustor at the University of Utah. The latest is a 4-inch diameter pyrolyzer and combustor with three, 1-inch diameter, potassium-filled heat pipes, each capable of conducting $4000^{\prime} \mathrm{Btu} / \mathrm{h}$. A scheriatic is shown in Figure 13 (Oblad et al. 1987). The fluid-bed pyrolyzer is subject to the same process parameter relationships as discussed in section 3.1 .1 .

This program has focused on extrapolation to commercial application, optimization and energy conservation, and economics. A simplified commercial configuration is shown in Figure 14 (Oblad et al. 1988). This configuration attains considerable energy utilization. After leaving the combustor, the flue gas goes through two economizing heat exchangers and a steam generator before going to atmosphere. Compressors are powered with internally generated steam using direct couple drives. Realistic assessments of required product selling price by this method have ranged from $\$ 25$ to $\$ 32$ per barrel, depending on conditions.

\subsubsection{Rotary Kiln Pyrolysis}

Another thermal extraction process being investigated by the University of Utah is a rotary kiln pyrolyzer. A unit has recently been built. Figure 15 shows the equipment layout (Oblad et al. 1988). Process variable tests are in the beginning stages.

Rotary kiln pyrolysis may overcome many of the process and economic problems inherent in fluidized beds: size reduction costs, fines handling, erosion, and particle attrition. Therefore, for some resources, rotary kiln pyrolysis may be more attractive than fluidized beds.

\subsubsection{Solvent Extraction}

As discussed in section 2.0 , bitumen is soluble in certain. solvents. The maltenes are soluble in aliphatic solvents (e.g.' hexane) and the asphaltenes are soluble in carbon disulfide and benzene. If solvents are well selected, essentially all the bitumen can be removed. Even if one of the bitumen constituents 


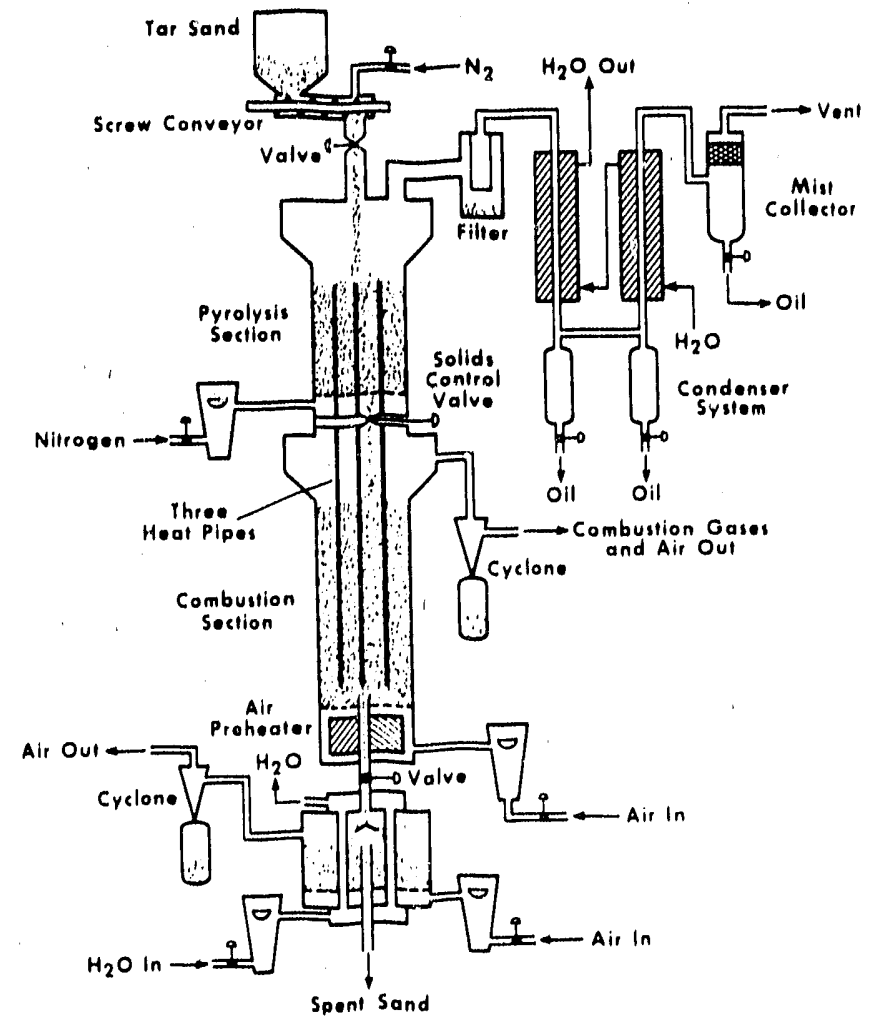

Figure 13. Fluidized-Bed Pyrolyzer/Leat-Pipe, Coupled Combuator

is not soluble in the solvent, it may be possible to disperse it in the solvent as an emulsion or colloid.

Several solvent extraction processes have been proposed in recent years. Because the processes are proprietary, essentially no information exists in the open literature as to solvent effectiveness and bitumen and solvent retention on the spent sand. The University of Utah is beginning a series of screening tests to first determine the feasibility of solvent processing. If any schemes appear promising, process variable tests will be done to bracket operability conditions.

\subsubsection{Water-Assisted Extraction}

The basis of the Canadian oil sands (water wet resource) industry is the water-assisted extraction scheme. Attempts to apply this technology to the domestic oil wet resource have not been successful without considerable modification. Figure 16 shows a simplified sequence of steps in the University of Utah process (Oblad et al. 1987). The digestion step involves the 


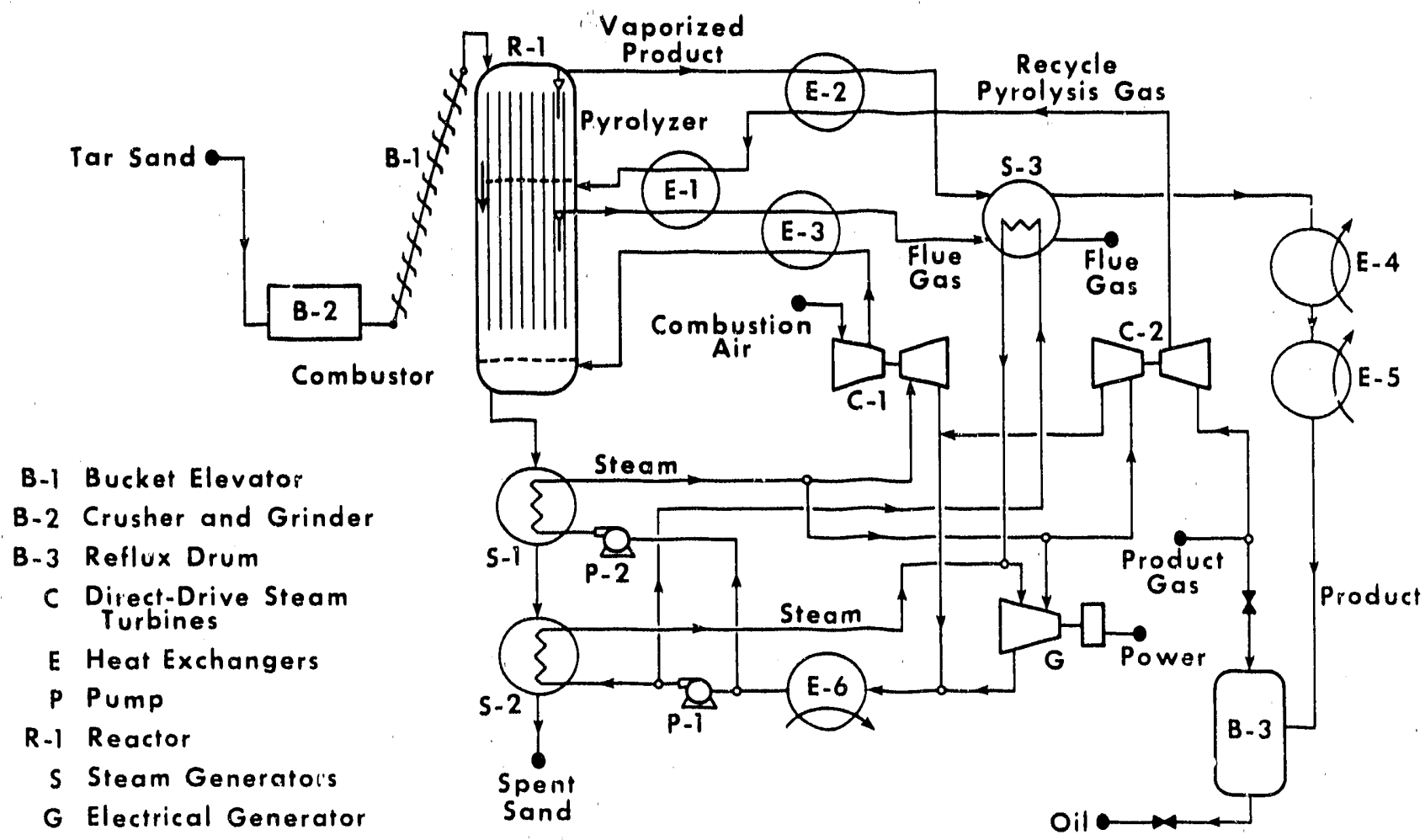

Figure 14. Simplified Schematic of Fluidized-Bed Pyrolyzer/Hoatpipe, Coupled, Coked, sand Combuator in Commercial Corsiguration

input of mechanical energy to the tar sand when hot water (originally 90 to $95^{\circ} \mathrm{C}$ [194 to $\left.203^{\circ} \mathrm{F}\right]$ ) is present. A diluent is added to reduce bitumen viscosity (typically kerosine or some relatively low boiling compound). A sodium salt is added as a wetting agent (sodium hydroxide, sodium silicate, and sodium carbonate have been used). Important experimental parameters have been bitumen viscosity, water $\mathrm{pH}$, sand particle size and distribution, temperature, and amount of agitation. Air is added to aid in bitumen-sand separation.

As found in work on numerous resources, a bitumen viscosity of about 10 poise is optimum for efficient extraction. This determines the amount of diluent and temperature required, since viscosity is strongly temperature dependent. In addition, wetting agent concentration goes through an optimum: too little concentration and it is ineffective; too much concentration and the base can cause emulsification problems.

The hot water process can recover more than 90 percent of the bitumen if conditions are optimized. In an effort to improve the economy of the process, digestion temperature has been lowered to $50^{\circ}$ to $60^{\circ} \mathrm{C}\left(122\right.$ to $\left.140^{\circ} \mathrm{F}\right)$. Figure 17 shows a more 


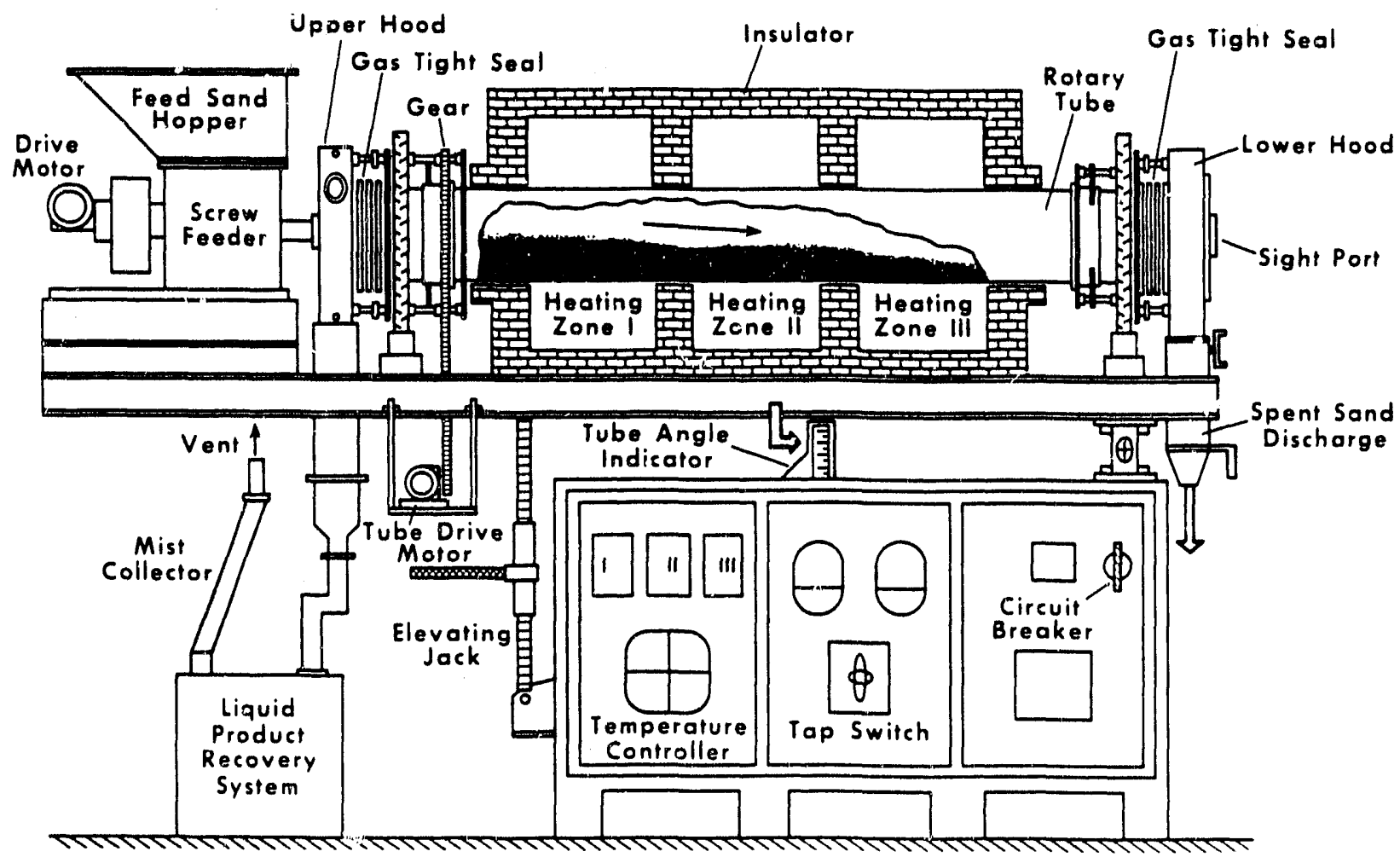

Figure 15. Rotary Riln Pyrolysis Unit

detailed schematic (Oblad et al. 1987). Not shown in the chart is the possible need for centrifuges to separate particulates from liquids. In addition, the thickening ponds and oil-skimming step may be on a considerable scale, depending on how cleanly the bitumen is removed from the tailings. Compared to Canadian deposits, typical Utah tar sand deposits contain less clay and produce less slime.

The University of Utah group will continue scale-up of the process to a larger PDU. Fundamental work in the area of bitumen/mineral interactions is being conducted. Process variables are being studied in a variety of domestic tar sands, and data to allow scale-up to pilot-plant size are being determined.

\section{3. ..6 Upgrading and Product Utilization}

In order for extracted tar sand bitumen to be used as a synfuels feedstock to refineries, it must be upgraded. Tar sand bitumen is solid at room temperature with large molecules. Thermal processing results in lower average molecular weights, viscosity, and pour points compared to the raw bitumen. Pyrolysis upgrades the product at the expense of liquid yield, and thus produces a suitable refinery feedstock. Water-assisted and solvent-recovery processes normally do not have any associated 


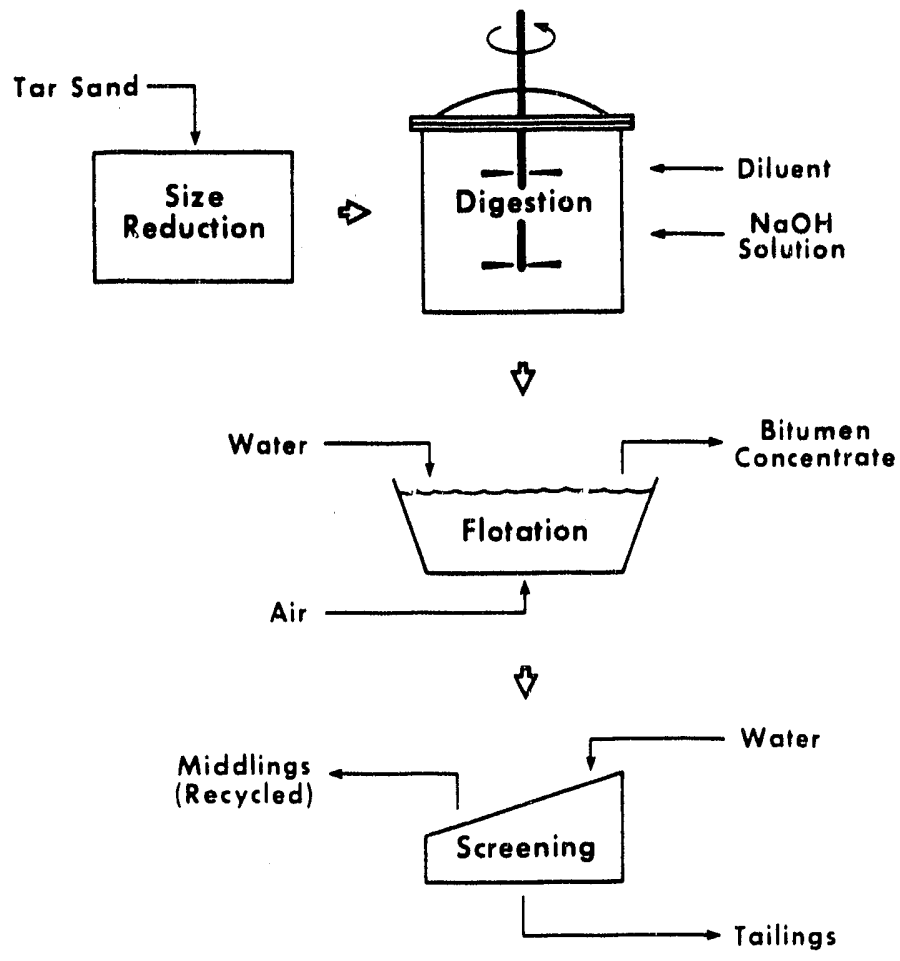

Figure 16. Simplified Water-Assisted Extraction Process

upgrading. Products frcm these processes are more suitable as asphalt components. In addition, produced tar sand bitumen can contain the heteroatoms oxygen, nitrogen, and sulfur regardless of the extraction process. Because the heteroatoms can be catalyst poisons and can cause polymerization and gum formation, they must be removed prior to refining. Some of the functional groups of the heteroatoms are stable and strongly resist reactions that would remove them. This is particularly the case when they are in ring structures, such as nitrogen in pyroles and pyridines. The traditional methods of removing these types of compounds has been high-pressure, high-temperature hydrogenation. This is an expensive procedure.

Before a refinery can accept tar sand bitumen as a feedstock, it must meet the specifications for that particular refinery. The bitumen product has froperties determined by both the deposit and the method of extraction. Matching product bitumen properties to refinery specifications can require considerable upgrading. Since upgrading costs can be several dollars per barrel, several methods must be available from which to choose to apply to bitumen from the many varied reservoirs. Numerous conventional upgrading processes are used for upgrading heavy oil or residuum for refinery utilization. Research applications of these existing processes is one of the first steps to reduce upgrading costs in this complicated technical picture. 


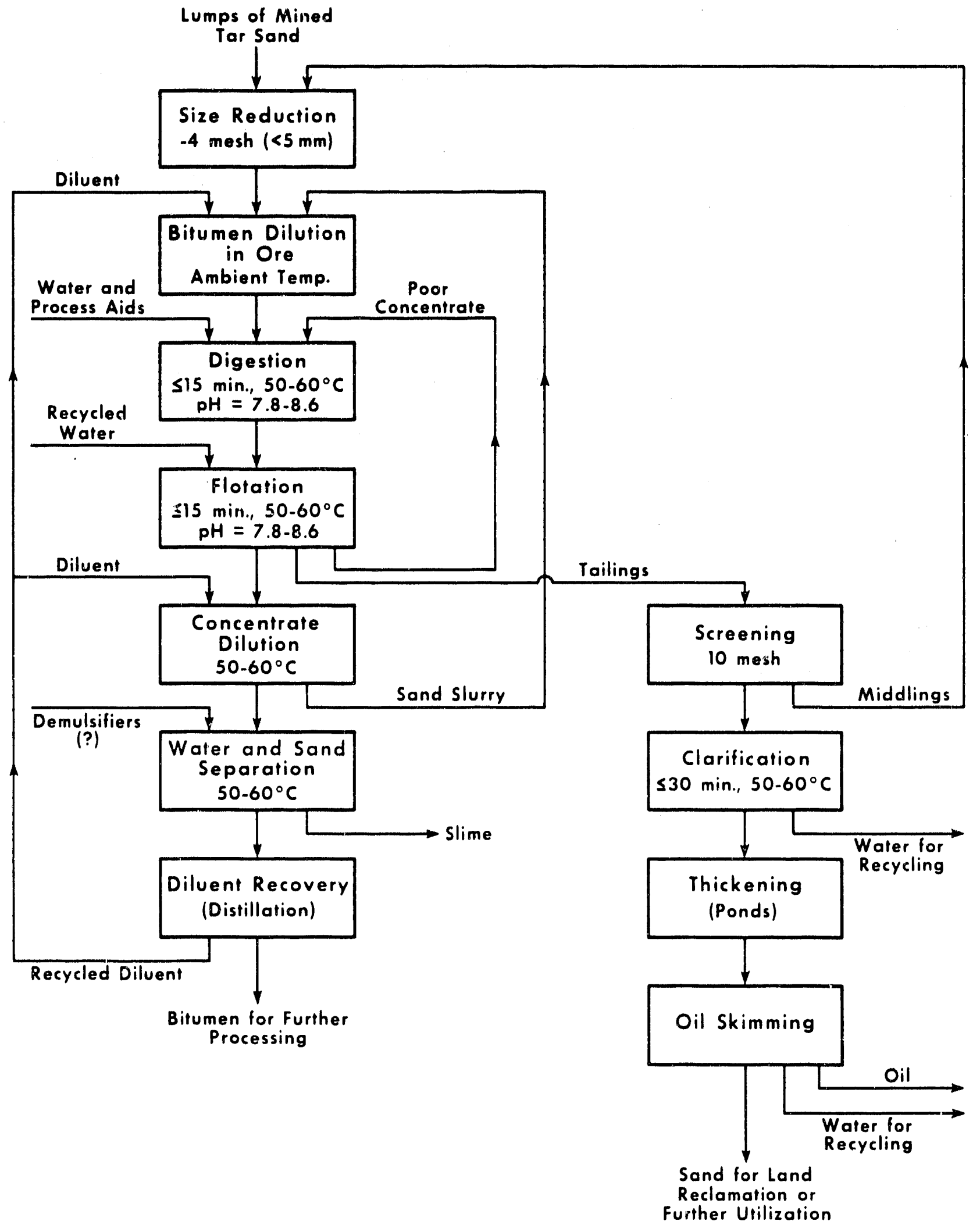

Figure 17. Modified Hot Water Separation Process 
Visbreaking is a mild thermal cracking process that reduces pour point and viscosity. Operating conditions are set to optimize the detachment of long chain paraffins from aromatic sings. Visbreaking has been used for upgrading tar sand bitumen (Oblad et al. 1987). Iiquid yields of 98 percent were obtained but further processing would be required anyway. The large molecules still remaining after visbreaking have poor accessibility to catalyst surfaces.

Delayed coking, flexicoking, and fluid coking are specific thermal upgrading processes that can significantly improve tar sand bitumen (Oblad et al. 1987). Coking is intended to maximize liquid yields while minimizing gas and coke. Low-pressure coking gives better than 83 percent liquid yields using tar sand bitumen. The gas production tends to be mostly methane, which limits its usefulness and value. As a by-product, it must compete with plentiful natural gas supplies, and it does not have chemical feedstock demand like ethane or propane.

Catalytic cracking is a more controlled and selective upgrading process that has also been experimentally applied to tar sand bitumen (Oblad et al. 1987) with nearly 80 percent liquid yields. Catalytic cracking usually produces less methane and heavier gases compared to coking. Applying this process to synthetic crude from tar sand may present problems because of metals content and heteroatoms.

Tar sand bitumen tends to have low hydrogen-to-carbon ratios compared to petroleum. Therefore, hydrogen addition results in upgrading. The traditional refinery hydrotreating and hydrocracking operations could well be applied to tar sands derived from synfuels. Hydrotreating catalytically stabilizes feedstocks by hydrogenation of unsaturated bonds (i.e., double bonds) and removal of nitrogen, oxygen, halides, and trace metals from the larger organic chains. Hydrocracking is a more severe operation that reduces average molecular weight (hence boiling range) in addition to the improvements brought by hydrotreating.

One of the commercially practiced upgrading routes in the Canadian industry has been coking followed by hydrotreating. This has yielded 65 to 70 percent liquids and large amounts of coke that cannot be utilized. It must be remembered that the Canadian extraction technology is the water-assisted process and the bitumen undergoes no appreciable thermal degradation upon recovery. Upgrading heavy tar sand bitumen without sacrificing product to coke could enhance process economics.

The University of Utah has developed a noncatalytic hydrogen addition process, called hydropyrolysis, that produces little coke from tar sand bitumen. A significant effect of the process is to reduce average molecular weight to the level where catalyst activity is not hindered by large molecular size. This is particularly important when hydrotreating is done to remove 
heteroatoms. The hydrogen-carbon ratio is also improved. The process involves spraying a fine mist of bitumen into a hot chamber using hot hydrogen gas as the aerosol carrier fluid. High temperatures, vapor phase state, and low residence times are desired. Therefore, the hydrogen is kept hot enough to quickly vaporize the liquid, and the flow rates are such that reaction residence time is small. When optimizod, liquid yield has been greater than 90 percent with essentially no coke formation.

To be most efficient, hydropyrolysis requires the liquid droplets to vaporize rapidly, and under some conditions, this process is delayed or is not complete. Thus some of the partially vaporized particles can impinge on the vessel walls, which has resulted in some coking. A large commercial vessel will have such a small surface-to-volume ratio (compared to the small experimental apparatus) that wall coking will be greatly reduced.

The current effort includes numerical simulation of the hydropyrolysis process. The developed model will enable the design of a 2-liter/hour tandem (series) hydropyrolysis and hydrotreater system. The effluents from the hydropyrolysis unit are a good feed for a hydrotreater, with some adjustments. When fabricated, the 2-liter/hour unit will undergo a series of process variable tests.

\subsection{University of Arkansas}

Work at the University of Arkansas is directed at solvent extraction of bitumen. In solvent extraction, the basic idea is to dissolve the bitumen in a suitable solvent. Light hydrocarbon aliphatic compounds work only because the asphaltenes can exist in them as emulsions. Aromatic solvents (e.g., benzene, toluene, and xylene) work because the bitumen dissolves in such compounds, except for the heavy (essentially solid) compounds. Another approach is to use a surfactant or amphiphile. These compounds have molecular parts that are attracted both to the bitumen and to the solvent.

Amphiphiles work by lowering surface tension between two phases. To illustrate the function of a surfactant, consider an immiscible mixture of oil and water. An appropriate surfactant would have both a hydrophobic and hydrophilic group. At high surfactant concentrations, the oil and water become miscible. At low concentrations, emulaification occurs because of the formation of micelles. Oleic acid, $\mathrm{CH}_{3}\left(\mathrm{CH}_{2}\right)_{7} \mathrm{CH}: \mathrm{CH}\left(\mathrm{CH}_{2}\right)_{7} \mathrm{CO}_{2} \mathrm{H}$, is an amphiphile that dissolves bitumen, prevents precipitation of asphaltenes, and is also a good carrier of the light hydrocarbons.

A group consisting of Diversified petroleum, Inc., and the University of Arkansas has developed a process (Wood-Beaver) that uses oleic acid as a solvent for extracting tar sand bitumen. $A$ 
schematic of the key extraction and solvent recovery steps are shown in Figure 18 (Couper 1989). Fresh tax sand feed is mixed with oleic acid and light aliphatic solvent (i.e., hexare) in an agitated vessel (contactor). The bitumen is solvated and is carried over to a phase separator where it mixes with an alcohol (isopropyl)/brine mixture. This causes the bitumen to dissociate where it is recovered for solvent removal and sales. The solvent/alcohol/brine solution is moved to a flash unit where most of the alcohol is driven off, causing the solvent and brine to eventually separate. All streams are then recycled. The process works on some delicate balances with the various phases. It is a sensitive extraction scheme that must be carefully adjusted for any given resource.

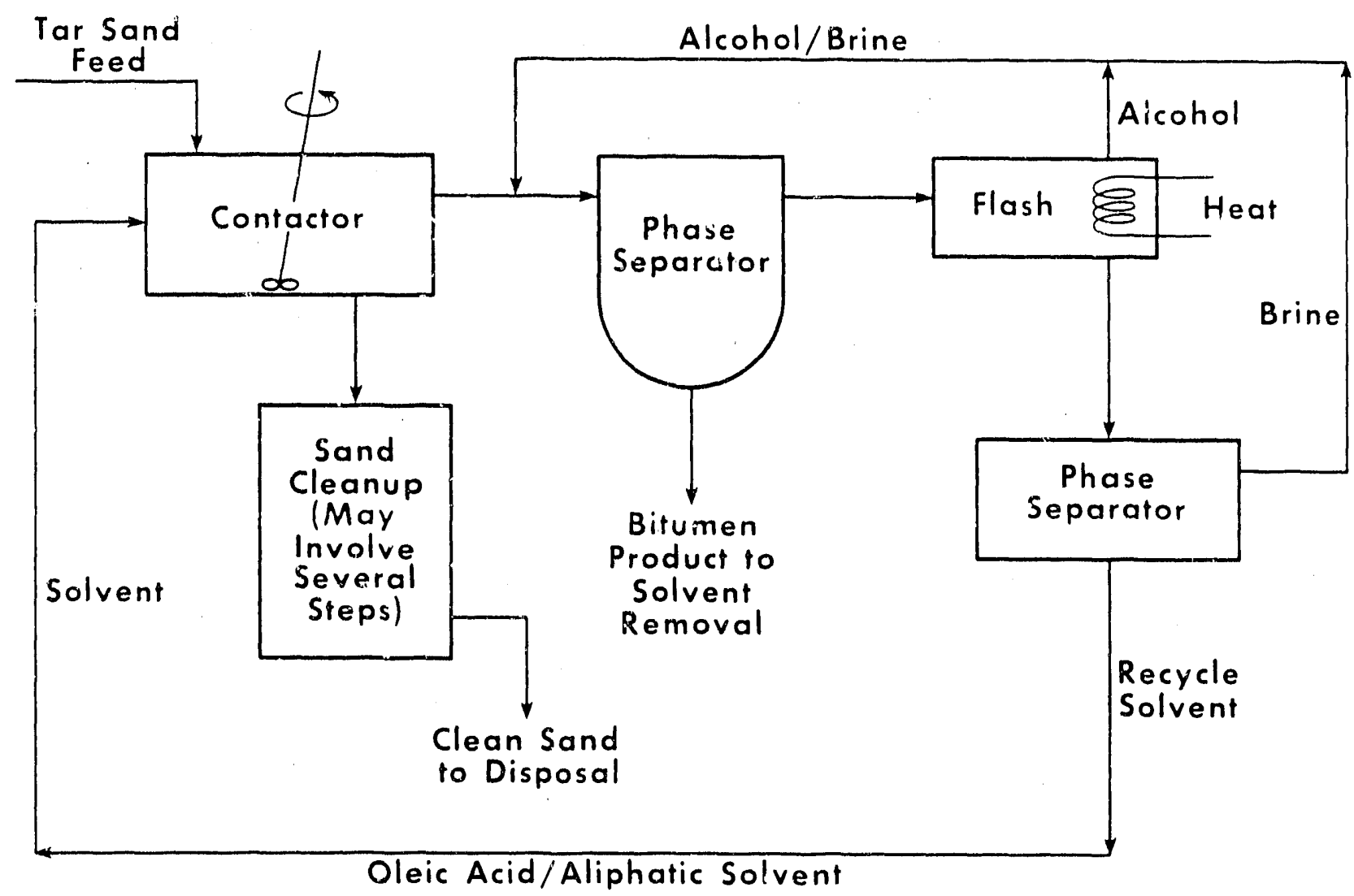

Eigure 18. Simplified Oleic Acid Extraction Scheme

This process is in the early stages of development. Two important problems have not been resolved:

- Solvent losses. The loss of oleic acid on the tailings has yet to be determined. It is not cost effective to lose 
expensive solvent to recover cheap bitumen. The distillation step also decomposes some oleic acid.

- Contaminants in recycle streams. It is yet to be determined whether or not contaminants that build up in the solvent recycle stream will disturb the predisted phase behavior. Complicated phase equilibria technology is more an art than science, and a priori predictions are not really possible.

\subsection{Westers Research Institute}

The Western Research Institute has developed an extraction scheme, using hot recycle bitumen, called the Recycle oil Pyrolysis and Extraction (ROPE) process (Cha et al. 1988). One of the cheapest solvents for tar sand bitumen is hot tar sand bitumen. Bitumen dissolves easily in itself, and in a processing plant, bitumen is obviously plentiful. Figure 19 shows the current configuration, which is a series of heated screw conveyors that process the tar sand in individual unit operations. The first two screws mix fresh feed with hot recycle oil. The second screw (preheating) has cocurrent oil and sand flow. In this screw,

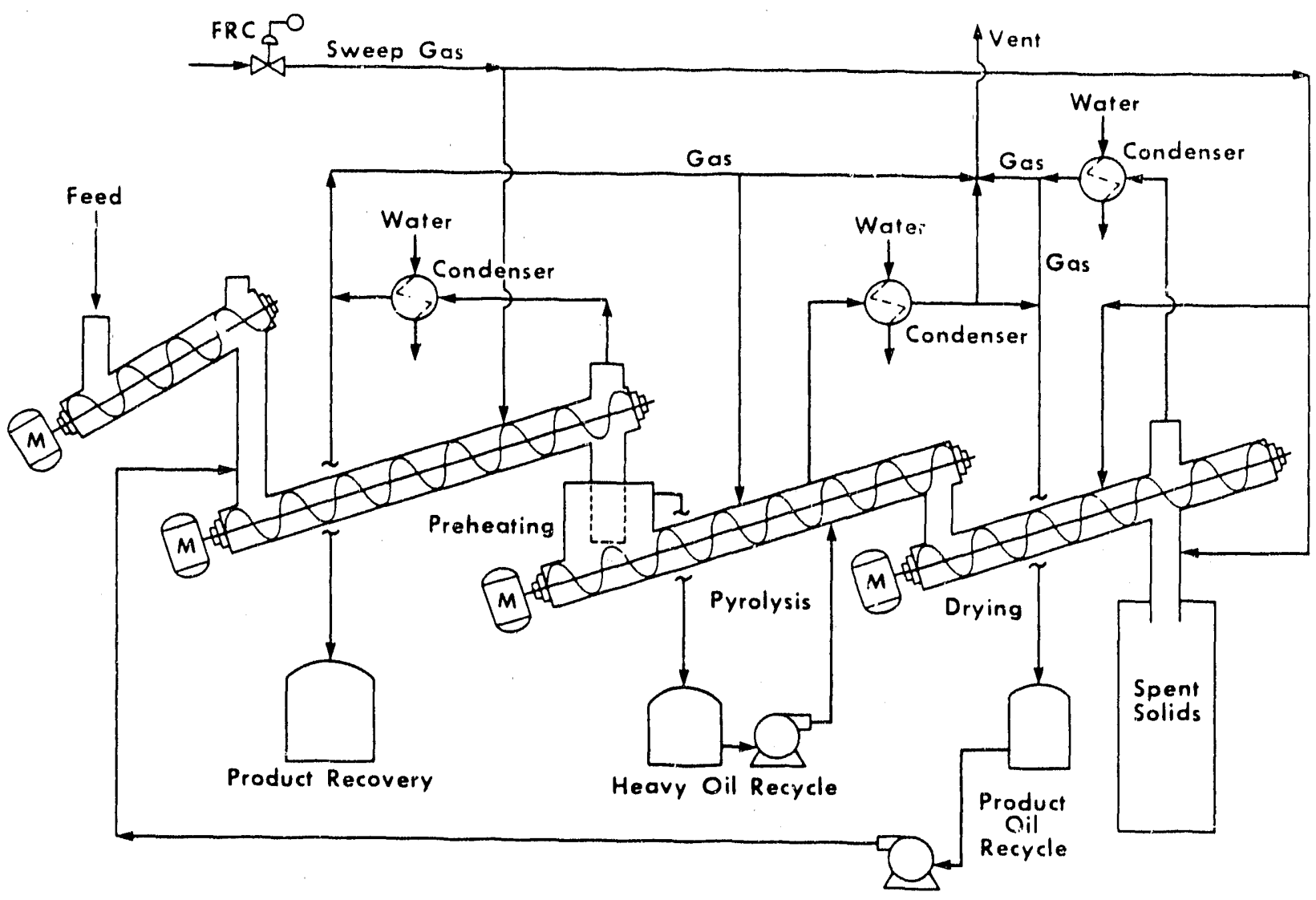

Figure 19. Six-Inch, RORE Rrocess Development Unit 
light ends flash $264^{\circ} \mathrm{C}\left(500^{\circ} \mathrm{F}\right)$ and are condensed and collected as product. In the third screw, pyrolysis, the temperature is about $349^{\circ} \mathrm{C}\left(660^{\circ} \mathrm{F}\right)$ and additional bitumen distills. The fourth screw, drying, operates at up to $524{ }^{\circ} \mathrm{C}\left(975{ }^{\circ} \mathrm{F}\right)$ and completes the pyrolytic extraction of any remaining heavy or residual bitumen.

The product tends to be a light, highly aromatic (greater than 90 percent by weight) synthetic fuel that does not require extensive upgrading. Preliminary tests indicate that the sand may have some catalytic effects, and there are indications of significant hydrogen donation from the recycle oil to the bitumen. Limited process variable tests have been done on selected resources, but there are still some needed, fundamental, mechanism studies before the process can be well understood. 


\subsection{CONCLUSIONS}

- The level of technology development is at the PDU scale for most of the extraction schemes appiicable to domestic tar sand resources.

- Considerable experimental work is needed to allow scale-up to pilot-plant size.

- Because of the wide variety of properties of domestic tar sand resources, development of multiple processes is essential.

- Costs of tar sand extraction will probably be in the $\$ 25$ to $\$ 30$ per barrel range, but because of the rapid decline in domestic crude oil production, synthetic fuels will be needed to offset the continually increasing oil imports. 


\subsection{REHTHRENCES}

Bunger, J.W. 1990. Costs for Production of Asphalt or Synthetic Crude Oil From Domestic Tar Sands. Unpublished Report to DOE.

Baughman, G.I. 1978. Synthetic Fuels Data Handbook. Cameron Engineers, Inc., 2 d ed., p. 3 .

Cha, C.Y., L.J. Fahy, and F.D. Guffey. 1988. DOE/MC/11076-2659. Asphalt Ridge Tar Sand Recovery Using the ROPE Process.

Couper, J.R. 1988. DE-FG21-88MC25043. Solvent Extraction of Southern U.S. Tar Sands: Annual Report. In Press.

Kuuskraa, V.A. 1985. Major Tar Sand and Heavy Oil Deposits of the United States. Paper presented at Third International Conference on Heavy Crude and Tar Sands, July 1985, Long Beach, California.

Marchant, I.C. 1985. U.S. Tar Sand Projects, 1985. Paper presented at Third International Conference on Heavy Crude and Tar Sands, July 1985, Long Beach, California.

Oblad, A.G., J.W. Bunger, F.V. Hanson, J.D. Miller, H.R. Ritzma, and J.D. Seader. 1987. Tax Sand Research and Development at the University of Utah. Annual Energy Review 1987. 12:283356 .

Oblad, A.G., J.W. Bunger, E.V. Hanson, J.D. Miller, and J.D. Seader. 1988. DE-FG20-84LC11057. Recovery and Upgrading of oil from Utah Tar Sands - Einal Report. In Press.

Oblad, A.G., and F.V. Hanson. 1988. DOE/MC/11090-2711. Production of Bitumen-Derived Hydrocarbon Liquids from Utah's Tar Sands - Einal Report.

Taciuk, W. Taciuk Processor Final Development Leading to Commercial Use in Oil Sands. Presented at AOSTRA Seminar, Advances in Petroleum Recovery and Upgrading Technology, June 6-7, 1985 , Edmonton, Alberta, Canada.

U.S. DOE. 1978. DOE/ET-0008/3. Underground Coal Program, Volume III Resources.

U.S. DOE Energy Information Agency. 1989a. DOE/EIA-0216 (88). U.S. Crude Oil Natural Gas, and Natural Gas Liquids Reserves 1988 Annual Report.

U.S. DOE Energy Information Agency. 1989b. DOE/EIA-0035 $(89 / 08)$. Monthly Energy Review - August 1989. 
U.S. Geological Survey (U.S.G.S.). 1989. Estimates of Undiscov= ered Oil and Gas Resources in the United States - A Part of the Nation's Energy Endowment. USGS/MMS Technical Report, United States Government Printing office. 


\subsection{TERMINOLOGY}

Aliphutic - Straight chain or branched organic compounds. May contain double- or triple-bonded carbon atoms.

Alkane - Straight chain or branched chain organic compound containing no multiple carbon-carbon bonds.

AlkyI - A paraffinic hydrocarbon radical.

Aromatic - Unsaturated cyclic hydrocarbon compounds (e.g., benzene).

Asphalt - Cementitious material, solid or semisolid, occurring naturally or derived from residual (bottoms) of petroleum refining. A mixture of all classes of hydrocarbons containing sulfur, nitrogen, and oxygen.

Asphaltene - Organic constituent of bitumen soluble in $\mathrm{CS}_{2}$, benzene, etc., but not in light paraffin (hexane). Molecular weights reported as greater than 2,000 and 10,000 to 100,000 . Densities as high as $1.22 \mathrm{~g} / \mathrm{cm}^{3}$. Polycyclic, aromatic compounds, normally polar and containing $O, N, S$, and various metals. polynuclear aromatic structures with long alkyl side chains linked together.

Colloid - Solid, liquid or gas dispersion of dimension less than $1 \mu \mathrm{m}$.

Emulsion - Stable liquid dispersed in another liquid.

Heteroatom - Compounds with atoms other than carbon and hydrogen present.

Maltene - Fraction of bitumen soluble in saturated aliphatic solvents (e.g., hexane).

Micelle - Groups of molecules with like functional groups aligned outward. They lead to formation of emulsions.

Rarafin - Straight chain hydrocarbon with no multiple carboncarbon bonds.

Polar - Having a permanent dipole moment or electrical charge.

Pour Point - The temperature at which a liquid will begin to pour from a container.

Resins - Dictionary definition is a high molecular weight solid (e.g., polymer). In tar sand jargon, it is a polar aromatic. 
saturatad - Having only singlu carbon-carbon bonds, c-c. Unaaturated - Having multiple carbon-carbon bonds, $c=c, c \equiv c$. viscosity - Resistance to fluid flow. 

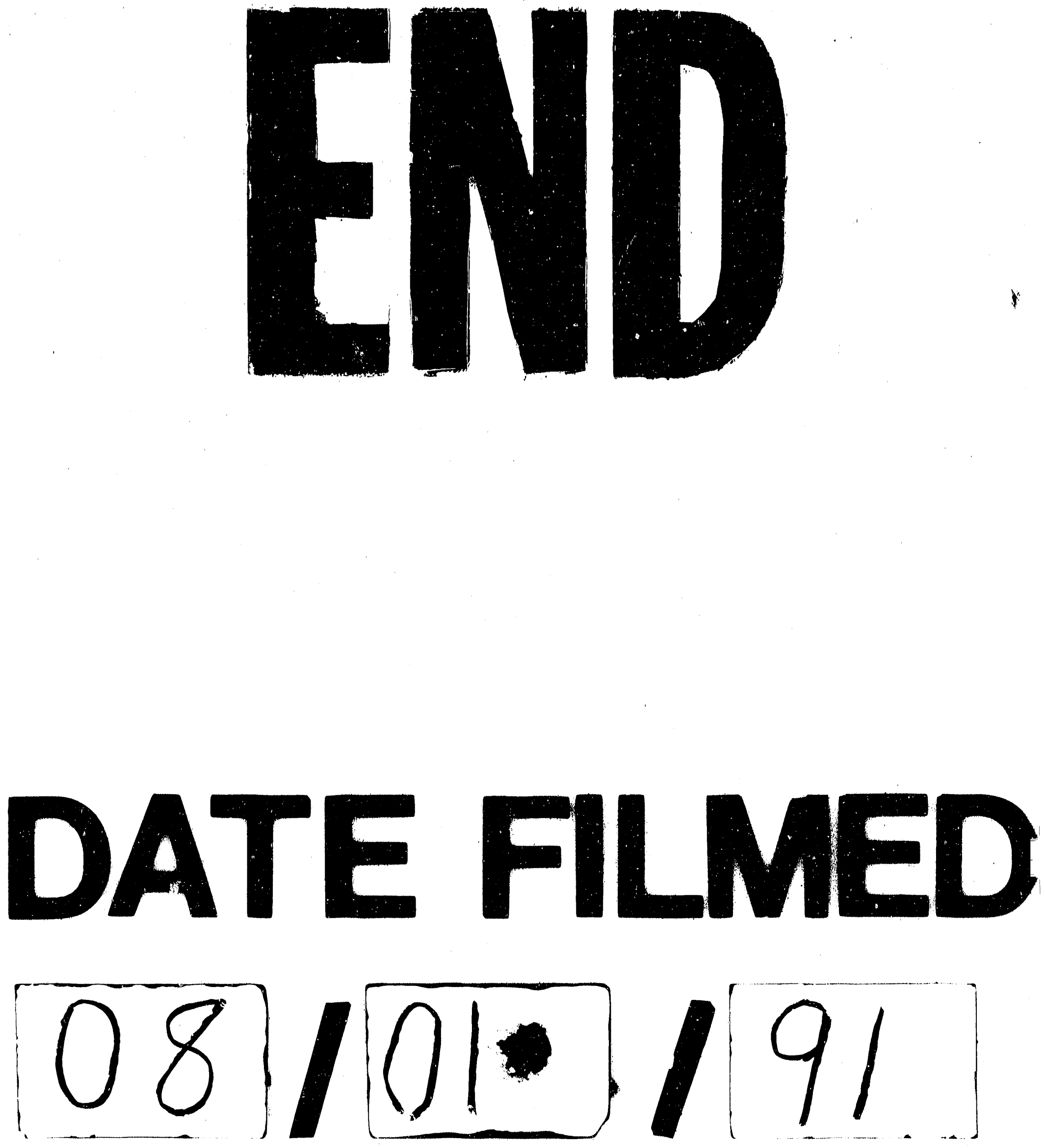